\title{
Aligning software engineering education with industrial needs: A meta-analysis
}

\author{
Vahid Garousi a,*, Görkem Giray ${ }^{\mathrm{b}}$, Eray Tüzün ${ }^{\mathrm{c}}$, Cagatay Catal ${ }^{\mathrm{a}}$, Michael Felderer ${ }^{\mathrm{d}, \mathrm{e}}$ \\ a Information Technology Group, Wageningen University, Wageningen, the Netherlands \\ ${ }^{\mathrm{b}}$ Independent Researcher, Turkey \\ ${ }^{c}$ Department of Computer Engineering, Bilkent University, Ankara, Turkey \\ d University of Innsbruck, Austria \\ e Blekinge Institute of Technology, Sweden
}

\section{A R T I C L E I N F O}

\section{Article history:}

Received 16 August 2018

Revised 11 March 2019

Accepted 9 June 2019

Available online 12 June 2019

\section{Keywords:}

Software engineering education

Industry needs

Important skills

Knowledge gap

Systematic literature review (SLR)

Meta-analysis

\begin{abstract}
A B S T R A C T
Context: According to various reports, many software engineering (SE) graduates often face difficulties when beginning their careers, which is mainly due to misalignment of the skills learned in university education with what is needed in the software industry.

Objective: Our objective is to perform a meta-analysis to aggregate the results of the studies published in this area to provide a consolidated view on how to align SE education with industry needs, to identify the most important skills and also existing knowledge gaps.

Method: To synthesize the body of knowledge, we performed a systematic literature review (SLR), in which we systematically selected a pool of 35 studies and then conducted a meta-analysis using data extracted from those studies.

Results: Via a meta-analysis and using data from 13 countries and over 4,000 data points, highlights of the SLR include: (1) software requirements, design, and testing are the most important skills; and (2) the greatest knowledge gaps are in configuration management, SE models and methods, SE process, design (and architecture), as well as in testing.

Conclusion: This paper provides implications for both educators and hiring managers by listing the most important SE skills and the knowledge gaps in the industry.
\end{abstract}

(C) 2019 Elsevier Inc. All rights reserved.

\section{Introduction}

The quality of the software engineering (SE) workforce is a direct result of the quality of SE education, and how SE students are trained. However, there is a widely-noted "gap" between software industry's skill needs and the education university students receive (Radermacher, 2012; Hire, 2019). While most university programs focus mainly on computer science (CS) core topics, SE topics get less attention (Radermacher, 2012). As early as in 1989, a paper by Ford and Gibbs (Ford and Gibbs, 1989) succinctly stated a problem that still partially exists today: "Somewhat oversimplified, industry needs software engineers, but universities are supplying computer scientists. Thus, it's time to promote widespread development of software engineering degree programs".

It has been reported that many recent SE graduates often face difficulties when beginning their professional careers

\footnotetext{
* Corresponding author.

E-mail addresses: vahid.garousi@wur.nl (V. Garousi), gorkemgiray@gmail.com (G. Giray), eraytuzun@cs.bilkent.edu.tr (E. Tüzün), cagatay.catal@wur.nl (C. Catal), michael.felderer@uibk.ac.at (M. Felderer).
}

(Radermacher, 2012; Hire, 2019). Some in the community believe that: "The software engineering shortage is not a lack of individuals calling themselves "engineers", the shortage is one of quality-a lack of well-studied, experienced engineers with a formal and deep understanding of software engineering" (Baker, 2019). It is widely accepted that better education of SE students will better prepare them for their SE careers after graduation and will increase their employability (American Society for Training Development, 2012). An effective approach to close the gap between academia and industry in SE education and to best train SE students is for both parties to work together on educational needs and goals (Beckman et al., 1997). If planned properly, such a collaboration can meet industry's education and training goals.

To address the above need, many studies ( 35 papers according to our literature search) have been conducted to "align" SE education with industry's skill needs. Each of those studies has focused on a regional and limited-scale dataset, usually gathered via opinion surveys. Thus, it is important to synthesize and aggregate the results of all those studies to provide a single "consolidated" view on how to align SE education with industry needs, and to find out the most important skills in the industry and the knowledge 
gaps, i.e., the SE topics that should get more education and training. As per the principles of meta-analysis (Cruzes and Dyba, 2010), combining and synthesizing data and evidence from all previous studies will provide a better and more comprehensive view on the topic.

To further motivate the need for such a meta-synthesis, the authors themselves are all active SE educators and have been teaching various SE courses for more than 15 years each. The authors have been involved in SE education research, e.g., (Garousi, 2011; Garousi and Mathur, 2010; Garousi, 2010a; Garousi, 2010b; Tuzun et al., 2018; Giray et al., 2016). Furthermore, they have had active industry experience or have worked in close collaborations with practitioners in many joint industry-academia collaboration projects, e.g., (Garousi et al., 2017; Cruzes et al., 2017) and have observed how engineers utilize their skills to conduct SE tasks and how lack of SE expertise could challenge an engineer doing her/his tasks. According to feedback from our industry partners who have hired our students, feedback from our recently-graduated students and needs of our university departments and SE programs, we have seen the need to synthesize the findings of studies in this area to best align SE education activities with industrial needs.

To conduct the analysis reported in this paper, we used the established guidelines and processes for performing systematic literature review (SLR) studies (Kitchenham and Charters, 2007) and meta-analysis (Cruzes and Dyba, 2010) in SE. Our systematic paper search and selection phase resulted in a set of 35 papers on this subject published between 1995 and 2018.

Our goal in this paper is to shed light on the importance and knowledge gaps of different SE topics and to answer the question of how to best train software engineers of tomorrow. By summarizing what we as a community know in that area, our article aims to benefit the readers (both educators and hiring managers) by providing both a "big picture" on the state of the community w.r.t. aligning SE education with industrial needs, and an "index" to the body of knowledge and evidence in that area. Furthermore, "because it is often impractical for readers to track down and review all of the primary studies [in this area], review articles [such as this work] are an important source of summarized evidence on a particular topic" (Garg et al., 2008).

The remainder of this article is structured as follows. Section 2 provides a review of related work. Section 3 describes the research method and the review planning. Section 4 presents the search phase and the selection of the pool of sources to be reviewed. Section 5 discusses the development of the systematic map and data-extraction plan. Section 6 presents the results of the literature review. Section 7 summarizes the findings and discusses the lessons learned. Finally, in Section 8, we draw conclusions and suggest areas for further research.

\section{A review of related works}

SE education and training are active areas among the "education research" and practitioners communities. The flagship conference in this area is the IEEE Conference on Software Engineering Education and Training (CSEE\&T), which was held for the 30th year in 2018. There are also various Computer Science (CS) education conferences, such as the ACM technical symposium on CS education (SIGCSE) which was held for its 49th year in 2018.

There is a very large number of papers in SE education. Since our goal in this work is to conduct a meta-analysis, the related works in our context are other survey/review papers (secondary studies) in this area. We searched for secondary studies in SE education and we were able to find seven such studies (Radermacher, 2012; Malik and Zafar, 2012; Heredia et al., 2015; Marques et al., 2014; Ouhbi et al., 2015; Radermacher and Walia, 2013; Aničić et al., 2017; Garousi et al., 2019), as listed in
Table 1. For each review study in Table 1, we include its publication year, the number of papers reviewed by the study, and the related research questions (RQs) studied in each paper. As one can see in Table 1, the earliest survey paper in this area was published in 2012, thus we see that secondary studies in this area are quite a recent phenomenon.

Out of the eight secondary studies in Table 1, only four (4) studies (Radermacher, 2012; Radermacher and Walia, 2013; Aničić et al., 2017; Garousi et al., 2019) have had RQs about aligning SE education with industrial needs. For example, one of the RQs in (Radermacher, 2012) was to determine: Is there empirical evidence of knowledge deficiencies in graduating computer science students?

We have added to Table 1 a column in which we objectively discuss the limitations of each of the three related studies (Radermacher, 2012; Radermacher and Walia, 2013; Aničić et al., 2017) and how our work addresses that limitation. In addition to those limitations, and also in addition to reporting knowledge gaps (our RQ 4), this meta-study provides extra novelty / insights w.r.t. the importance of SE skills (our RQ 3 in Section 6.4). We should highlight that, as one RQ of our study (RQ 8), we will compare our results to findings of those review papers when the data are comparable (in Section 6.8).

It should be mentioned that a short version of the current work has recently been accepted for publication in IEEE Software (Garousi et al., 2019). The main difference between the paper at hand and the short version published in IEEE Software is that the this full paper targets researchers and SE educators, whereas the IEEE Software article (Garousi et al., 2019) targeted mainly practitioners. Therefore, in the IEEE Software article we reported only the following three of the overall eight RQs, and also covered them in less detail and more from a practitioner's perspective compared to this full paper:

- What skills are the most important in the software industry? (RQ 3)

- Is there evidence of knowledge deficiencies in graduating SE students? (RQ 4)

- To what extent are soft skills important, in addition to hard (technical) skills? (RQ 5)

\section{Research method and SLR planning}

In this section, we present an overview of our research method (Section 3.1) and then the goal and research questions of our study (Section 3.2). The authors should note that since SLRs in SE has a standard and established process (Kitchenham and Charters, 2007), the process and text of the current Sections 3-5 are quite similar to the other SLRs published by other researchers and by the authors in the past, e.g., (Garousi et al., 2016; Doğan et al., 2014).

\subsection{Overview}

We developed the SLR process as illustrated in Fig. 1. The process was developed based on our past experience in systematic mapping (SM) and SLR studies, e.g., (Garousi et al., 2016; Doğan et al., 2014), and the well-known guidelines for conducting literature reviews and meta-analysis in SE (e.g., (Cruzes and Dyba, 2010; Kitchenham and Charters, 2007; Petersen et al., 2015; Wohlin, 2014; Petersen et al., 2008)). As shown, part of the work is a SM in which we categorized the primary studies w.r.t. a set of defined attributes. Another component of our work is the metaanalysis of quantitative data about the importance of SE skills, and knowledge gaps, as extracted from the primary studies.

The next subsection gives an overview of the design of SLR along with its goal and RQs. The subsequent phases are presented in the Sections 4-6. 
Table 1

A list of other survey (review) papers on aligning SE education with industrial needs.

\begin{tabular}{|c|c|c|c|c|c|}
\hline Paper title & Year & Reference & $\begin{array}{l}\text { Type of } \\
\text { secondary } \\
\text { study }\end{array}$ & $\begin{array}{l}\text { Num. of } \\
\text { papers } \\
\text { reviewed }\end{array}$ & $\begin{array}{l}\text { RQs / objectives related to our } \\
\text { scope (aligning SE education } \\
\text { with industrial needs) }\end{array}$ \\
\hline $\begin{array}{l}\text { Evaluating the gap } \\
\text { between the skills and } \\
\text { abilities of senior } \\
\text { undergraduate computer } \\
\text { science students and the } \\
\text { expectations of industry }\end{array}$ & 2012 & (Radermacher, 2012) & $\begin{array}{l}\text { Systematic } \\
\text { literature } \\
\text { review } \\
\text { (SLR) }\end{array}$ & 28 & $\begin{array}{l}\text { 1. Is there empirical evidence of } \\
\text { knowledge deficiencies in } \\
\text { graduating computer science } \\
\text { students? } \\
\text { 2. How do the knowledge } \\
\text { deficiencies that have been } \\
\text { identified by academia and } \\
\text { industry differ? } \\
\text { 3. Can a classification system for } \\
\text { the identified knowledge } \\
\text { deficiencies be created? }\end{array}$ \\
\hline
\end{tabular}

Gaps between industry
expectations and the expectations and the
abilities of graduates

\section{$2013 \quad$ (Radermacher and SLR} Walia, 2013)

2014

(Marques et al., 2014)

Systematic mapping approaches to teaching software engineering

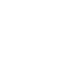

\footnotetext{
1. Is there empirical evidence of knowledge deficiencies in graduating computer science students?
}

2. What are the most common knowledge deficiencies in students?

3. Are there trends or changes in knowledge deficiencies in students over time?

- RQ1: What are the main approaches used to address the practical experiences in software engineering education?

- RQ2: Is there an emerging tendency to address this challenge [practical experiences]?

- RQ3: Which software process models are used to support the practical experiences in software engineering courses?

- RQ4: Have the universities changed the way of conducting these experiences over the years?

1. Does the paper stress the need for changes in curriculum design and delivery?

2. Does the paper stress the mismatch between learnin outcomes of ICT graduates and skills requirements from the labor market?

3. Does the paper stress the need for different/new teaching and assessment methods?
Limitations of the study / How our work addresses that limitation

The body of knowledge used in the study was ad-hoc (not an established one), while we are using the Software Engineering Body of Knowledge (SWEBOK) v3 (Bourque and Fairley, 2014). The study marked whether each primary study mentioned the knowledge deficiency a SE topic as a Boolean (yes/no), while our study uses the relative ranking data from the primary studies (see Section 6.4). Such ranking data would provide more precise aggregate data at the end of the meta-analysis.

The same limitations as discussed for (Radermacher, 2012) above

The same limitations as discussed for (Radermacher, 2012) above
The RQ 2 was addressed very briefly and only with general non-quantitative results. Our SLR synthesizes knowledge gap data quantitatively.
Closing the gap between software engineering education and industrial needs
2019 (Garousi et al., 2019) Meta-
synthesis

The short version of the work reported in this paper, published in IEEE Software, which reported only three of the RQs, and in less detail and more from a practitioner's perspective compared to this paper

\subsection{Goal and research questions}

The goal of this study is to systematically classify, review, and synthesize the body of knowledge and evidence in the scope of aligning SE education with industrial needs, from the point of view of educators and hiring managers. We raised the following research questions (RQs) to achieve our goal:

- RQ 1-Types of data collection methods and metrics: What types of data collection methods have been used in the stud- ies? We observed that while some studies use opinion surveys to gather data, others use interviews or mine job advertisements to extract the data to conduct their analysis. Also, what metrics have been used? Some related metrics are: how much a given subject has been learned by students in university programs, and how much engineers currently know about a given subject?

- RQ 2-Curriculum models (bodies of knowledge): What curriculum models (bodies of knowledge) have been used to design the studies? Some examples are the Software Engi- 


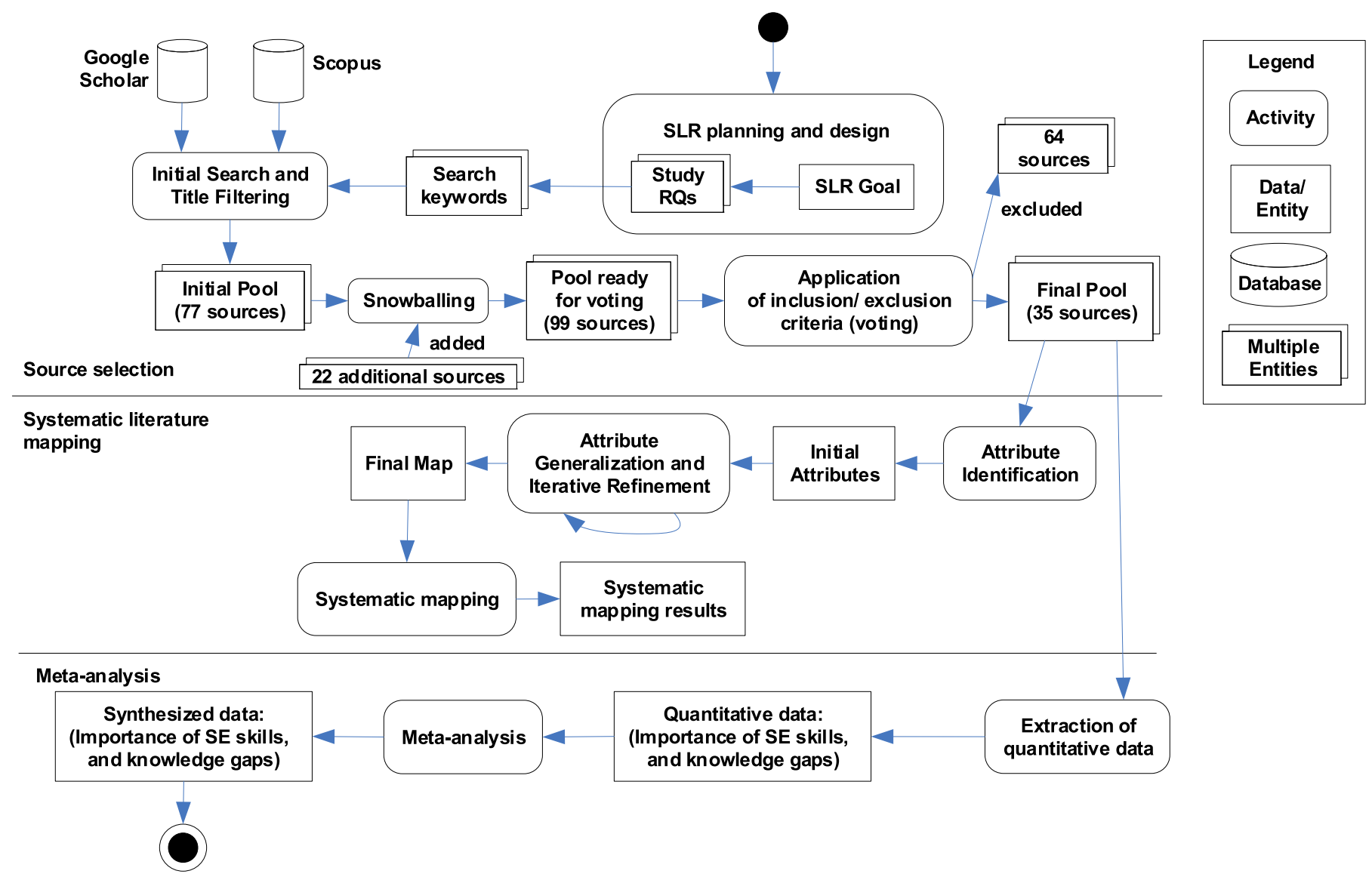

Fig. 1. An overview of the applied SLR process (represented as a UML activity diagram), similar to the process in our previous SLRs (Garousi et al., 2018).

neering Body of Knowledge (SWEBOK) (Bourque and Fairley, 2014), the Software Engineering Education Knowledge (SEEK) (Sobel, 2003), and the ACM SE 2004 curriculum guideline (Institute for Electrical and Electronic Engineers (IEEE-CS) and Association for Computing Machinery (ACM) 2004).

- RQ 3-Importance of SE skills: Which SE skills (subjects) are the most important and which SE subjects are the least important for a typical software engineer in practice?

- RQ 4-Knowledge gaps (deficiencies): What is the evidence for knowledge gaps (deficiencies) in different SE subjects? And what are the topics with the highest knowledge deficiencies?

- RQ 5-Importance of soft skills: What is the evidence on the importance of soft skills? And to what extent are soft skills important, in addition to technical ("hard") skills?

- RQ 6-Dataset (data sample) characteristics: What are the characteristics of the data sample? For example, what is the number of data points (e.g., participants, job advertisements) in the survey conducted by a given study? Which region (countries) are covered by the surveys?

- RQ 7-Synthesis of educational recommendations/findings: What educational recommendations are provided in each study? We wanted to synthesize such recommendations for the benefit of educators and hiring managers.

- RQ 8-Comparison of our results to previous review papers: How do the findings of our meta-analysis (importance of SE skills, and knowledge gaps) compare to the findings of previous review papers (Radermacher, 2012; Radermacher and Walia, 2013; Aničić et al., 2017) (which had similar objectives), as discussed in Section 2?
We should note that a shorter version of this work, covering only RQs 3-5, has been prepared as a short paper (Garousi et al., 2019). Thus, the current paper is a "major" extension of that short paper.

\section{Searching for and selection of primary studies}

As Fig. 1 illustrates, we searched for and selected primary studies in the first phase, which consists of three steps, as discussed next. Section 4.1 presents source selection and search keywords. Section 4.2 summarizes how we applied inclusion and exclusion criteria, and Section 4.3 gives an overview of the final pool of papers and the online repository.

\subsection{Selecting the source engines and search keywords}

We performed the searches in two online academic search engines (paper databases): Google Scholar and Scopus (www.scopus.com), which are widely used in SLR studies, e.g., (Garousi and Mäntylä, 2016; Garousi, 2015). The reason that we used Scopus along with Google Scholar was that several sources have mentioned that: "it [Google Scholar] should not be used alone for systematic review searches" (Haddaway et al., 2015) as it may not be sufficient to find all relevant papers. Several SLRs in SE also use other digital libraries such as ACM Digital Library, IEEE Xplore, Springer, and ScienceDirect. There are empirical studies in information and library sciences, such as (Jacsó, 2005), which have shown that Google Scholar indexes and sufficiently covers other well-known digital libraries such as ACM Digital Library, IEEE Xplore, Springer, and ScienceDirect. To validate our search strategy 


\begin{tabular}{|c|c|c|c|}
\hline$\equiv$ & Google Scholar & (educational needs OR knowledge needs OR desired skills OR essential com $Q$ & \\
\hline - & Articles & About 235,000 results $(0.24 \mathrm{sec})$ & \\
\hline & $\begin{array}{l}\text { Any time } \\
\text { Since } 2018 \\
\text { Since } 2017 \\
\text { Since } 2014 \\
\text { Custom range... }\end{array}$ & $\begin{array}{l}\text { Critical skills and knowledge requirements of IS professionals: a joint } \\
\text { academic/industry investigation } \\
\text { DMS Lee, EM Trauth, D Farwell - MIS quarterly, } 1995 \text { - JSTOR } \\
\text {.. We argue further that the concept of a generic curriculum to meet the educational needs of all future } \\
\text { IS professionals is ... } 50 \text { people from various industries and universities, an initial set of issues } \\
\text { regarding IS human re-source needs in industry and education was rec ... } \\
\text { } 50 \text { Cited by } 1104 \text { Related articles All } 12 \text { versions Import into EndNote }\end{array}$ & [PDF] jstor.org \\
\hline & $\begin{array}{l}\text { Sort by relevance } \\
\text { Sort by date } \\
\checkmark \text { include patents } \\
\checkmark \text { include citations } \\
\square \text { Create alert }\end{array}$ & $\begin{array}{l}\text { Educational needs as perceived by IS and end-user personnel: A survey of } \\
\text { knowledge and skill requirements } \\
\text { RR Nelson - Mis Quarterly, } 1991 \text { - JSTOR } \\
\ldots \text { self-perception becomes a viable means for evaluating the educational needs of personnel ... the } \\
\text { literature has clearly distinguished between organizational and func- tional learning, education } \\
\text { and training ... and knowledge and skills, while suggesting that the learning needs of both ... } \\
\text { S } 59 \text { Cited by } 374 \text { Related articles All } 10 \text { versions Import into EndNote }\end{array}$ & [PDF] jstor.org \\
\hline & & $\begin{array}{l}\text { [PDF] Knowledge management in software engineering } \\
\text { I Rus, M Lindvall, S Sinha - IEEE software, } 2002 \text { - pdfs.semanticscholar.org } \\
\ldots \text { effect that a long-term investment such as knowledge management and learning for the .... start with, } \\
\text { it is clear that a knowledge management system needs to be ... and leading a project - Technical } \\
\text { (engineering/development) knowledge refers to development knowledge and skills ... } \\
\\
\text { D Cited by } 944 \text { Related articles All } 18 \text { versions Import into EndNote Do }\end{array}$ & [PDF] semanticscholar.org \\
\hline & & $\begin{array}{l}\text { Inside a software design team: knowledge acquisition, sharing, and integration } \\
\text { DB Walz, JJ Elam, B Curtis - Communications of the ACM, } 1993 \text { - dl.acm.org } \\
\ldots \text { to develop a prototype of the object server in Pro- log for (personal) educational pur- poses ... } \\
\text { Beginning in the middle of August, discussions related to technical knowledge, re- quirements, } \\
\text { and design ... see Figure 2). In the early meet- ings, the team focused on learning what they ... }\end{array}$ & [PDF] researchgate.net \\
\hline
\end{tabular}

Fig. 2. A screenshot from the search process using Google scholar.

and to reduce threats to validity we conducted our own validation and re-executed the searches with our keywords (discussed below) in ACM and IEEE Xplore. We then checked the first 5 pages of each result set and did not find any additional papers not yet included. Thus, it made sense to use the "subsuming" (larger) index which anyways would find items in each of the above individual digital libraries.

All authors conducted searches in Google Scholar and Scopus using the search string independently. When searching, the authors decided on which papers to include by applying inclusion and exclusion criteria. The search string was: (educational needs OR knowledge needs OR desired skills OR essential competencies OR knowledge requirements OR skill requirements) AND (software engineers OR software developers).

The searches were conducted in winter 2018. Data extraction from the primary studies and their classifications were conducted during the winter and spring 2018. We wanted to include all the papers on this topic, thus we did not restrict the papers' year of publication (e.g., only those after 2000).

To ensure the inclusion of directly- or potentially-relevant papers, we applied title filtering to make our paper search and selection efforts efficient. To this end, we used the first inclusion/exclusion criterion (i.e., Does the source focus on aligning SE education with industrial needs?). Fig. 2 illustrates a sample screenshot of some results we obtained from Google Scholar. As is seen from Fig. 2, some results are directly- or potentiallyrelevant (highlighted by green boxes) and some are the clear out-of-scope papers (highlighted by red boxes). To best manage the efficiency of our efforts, we only added the related studies to the candidate pool. We had taken a similar approach in our provost SM and SLR studies (Doğan et al., 2014; Zhi et al., 2015; Garousi et al., 2015; Häser et al., 2014; Felderer et al., 2015; Felderer and Fourneret, 2015).
Another issue was the stopping condition when searching using Google Scholar. As Fig. 2 shows, Google Scholar provided a very large number of results using the search string (more than 200,000 records). It is impossible to go over all of the results. We utilized the relevance ranking of Google Scholar (Google's PageRank algorithm) to restrict the number of results. We checked the results in the first $\mathrm{n}$ pages and stopped checking when we could not find any relevant paper in the $\mathrm{n}^{\text {th }}$ page. Several other review studies, guideline and experience papers (Godin et al., 2015; Mahood et al., 2014; Adams et al., 2016; Garousi and Mäntylä, 2016; Garousi et al., 2017) have reported the use of a similar heuristics. As Fig. 1 shows, our initial pool consisted of 77 papers in consequence of our initial search and title filtering.

Also, since both Scopus and Google Scholar were used, there were chances of duplications in the pool. We only added to the pool a candidate paper if it was not already in the candidate pool.

As recommended by systematic review guidelines, we also conducted forward and backward snowballing (Wohlin, 2014) on the papers already in the pool, to include all the relevant sources as much as possible. Backward snowballing involves the application of inclusion/exclusion criteria to the reference list of a paper that is already in the pool. In forward snowballing, inclusion/exclusion criteria are applied for the papers citing a paper that is already in the pool. Both forms of snowballing are often used in SLR/SM studies for identifying further related papers (Wohlin, 2014).

We found 22 additional papers using snowballing. For instance, paper [P4] was found by "forward" snowballing of [P33]. Papers [P31] and [P32] were found by forward snowballing of [P1]. Note that the citations in the form of [Pn] refer to the IDs of the primary studies (papers) reviewed in our study. They are available in the study's online spreadsheet (goo.gl/HU9Wz4).

The initial pool was composed of 99 "candidate" papers. The authors conducted a systematic voting (as discussed next), in 


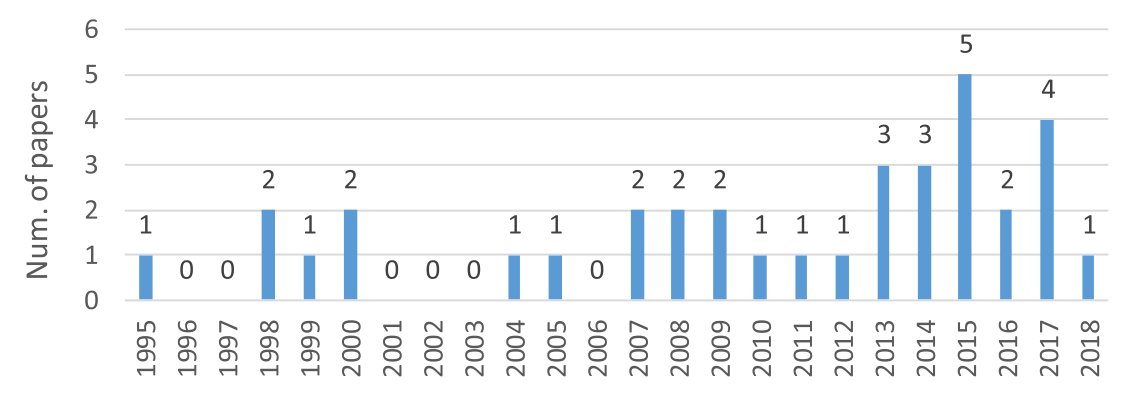

Fig. 3. Growth of the field over the years.

which a set of defined inclusion/exclusion criteria were applied to derive the final pool of the primary studies.

We should highlight that there is no perfect search strategy in SLRs, as we have learned in conducting and publishing several systematic literature reviews in software engineering, e.g., (Garousi et al., 2016; Doğan et al., 2014). We have made all our effort to minimize the chances of missing relevant papers, but of course there is no guarantee for that. This issue has been discussed elsewhere as well, e.g., in the medical sciences (Greenhalgh and Peacock, 2005).

\subsection{Application of inclusion/exclusion criteria and voting}

We carefully defined the following inclusion criteria to ensure including all the relevant sources and not including the out-ofscope sources. The inclusion criteria were as follows:

- Does the paper focus on aligning SE education with industrial needs?

- Is the paper based on empirical data and not just the opinion of the authors?

- Is the source in English and can its full-text be accessed on the Internet?

The answer to each question could be binary: either Yes (value $=1$ ) or No (value $=0$ ). Our voting approach was as follows. One of the researchers voted on all the candidate papers w.r.t. all the above three criteria. The other researchers then peer-reviewed all those votes. We used a consensus approach where disagreements were discussed until consensus was reached among all authors.

We included only the sources which received 1 's for all the above three criteria and excluded the rest. Application of the above criteria led to exclusion of 64 sources, details for which can be found in the study's online spreadsheet. For example, we excluded (Wohlin and Regnell, 1999; Faulk, 2000) since they were not based on empirical data but rather based on only the opinions of the authors. Many papers had a remote relation to "SE" education and had not considered a reasonable set of SE topics, but rather had focused on IS (information systems) or IT education, which we excluded, e.g., (Benamati et al., 2010; Kim et al., 2006). The entire list of excluded papers with their exclusion reasons are available in the "Excluded" tab the online spreadsheet (goo.gl/HU9Wz4).

\subsection{Final pool of the primary studies}

The list of the final pool of 35 papers can be found in an online spreadsheet at goo.gl/HU9Wz4. Once we finalized the pool of papers, we looked at the growth of this field by the number of published papers per year. We depict in Fig. 3 the annual number of papers (by their publication years). Note that, as discussed in Section 4.1, since we searched for the papers during winter 2018, the number of papers for 2018 is partial (only one paper).
We see in Fig. 3 that researchers have been active in the area since the mid 1990's and the annual number of papers had reached its maximum in the year 2015 (5 papers). Fig. 3 shows that, although SE has been taught in many universities and colleges around the world for several decades now, SE educators still struggle to properly align SE education with industrial needs, as visible by the number of recent studies.

\section{Development of the systematic map and meta-analysis plan}

As discussed in our SLR process (Fig. 1), one of the two activities in our SLR is a SM in which we wanted to categorize the primary studies w.r.t. a set of defined attributes (RQs). To achieve this, we developed a systematic map and then extracted data from the papers to classify them using the map. In this section, we discuss the development of the systematic map (Section 5.1), and then the process for data extraction and meta-analysis (Cruzes and Dyba, 2010) (Section 5.2).

\subsection{Development of the systematic map}

The first step in developing our systematic map was the analysis of the studies in the pool and the identification of the initial list of attributes. We derived the final map by generalizing and refining the initial attributes, as shown in Fig. 1.

We recorded the studies, which we identified as relevant, in our online spreadsheet to facilitate further analysis. Next, we categorized the studies to answer the RQs and build a current picture of the research area. We synthesized the findings of the primary studies and built a systematic map iteratively.

Table 2 shows the final systematic map (classification scheme) that we developed after applying the process described above. In the table, column 1 shows the study's RQs, column 3 shows the corresponding attribute/aspect of each RQ, and column 4 shows the set of all possible values for the attribute. Column 4 indicates, for an attribute, whether multiple or single selections of values can be applied. For example, for RQ 1 (types of data collection method), the corresponding value in the last column is " $\mathrm{M}$ " (Multiple), indicating that one study can contribute more than one data collection method (e.g., opinion survey, interviews, data from mining job advertisements, etc.). In contrast, for RQ 3 (base models used), the corresponding value in the last column is " $\mathrm{S}$ " (Single), indicating that one paper has used only one base model.

The last column in Table 2 shows the chosen research approach to answer each RQ. To find the suitable research approaches, we studied the guidelines for selecting empirical methods for SE research (Easterbrook et al., 2008), and also the guidelines for performing SLR (Kitchenham and Charters, 2007). Due to the type of each $R Q$, we found that four of the eight RQs (as shown in the table) should be addressed by conventional systematic mapping (SM), based on attributes listed in Table 2.

For two RQs (RQ 3 and RQ 4), since our goal was to find the (degree of) evidence for importance of and knowledge gaps in SE 
Table 2

\begin{tabular}{|c|c|c|c|c|}
\hline RQ & Attribute/Aspect & Categories & $\begin{array}{l}\text { (M)ultiple/ } \\
\text { (S)ingle }\end{array}$ & $\begin{array}{l}\text { Research } \\
\text { approach }\end{array}$ \\
\hline \multirow[t]{2}{*}{1} & $\begin{array}{l}\text { Types of data collection } \\
\text { method }\end{array}$ & $\begin{array}{l}\text { \{Opinion survey, Interviews, Data from mining job } \\
\text { advertisements, Other\} }\end{array}$ & $\mathrm{M}$ & \multirow[t]{2}{*}{ SM } \\
\hline & Types of metrics used & $\begin{array}{l}\text { SHow much learned in university, how much a software } \\
\text { engineer knows about a topic currently, How important } \\
\text { (needed, relevance) a topic is, Usage and usefulness of the } \\
\text { topic in work, Knowledge gap (deficiency)= } \\
\text { learned-importance, Other\} }\end{array}$ & M & \\
\hline 2 & $\begin{array}{l}\text { Base models (bodies of } \\
\text { knowledge) used }\end{array}$ & $\begin{array}{l}\text { \{SWEBOK v } 1.0 \text { (1999), SWEBOK v2. (2004), SWEBOK v3 } \\
\text { (2014), SEEK 2003, ACM SE 2004, ACM SE 2014, ACM computer } \\
\text { engineering curricula (2004), ACM computer science curricula } \\
\text { (CCCS) (2013), ACM IT curriculum (2017), ACM IS curriculum } \\
\text { (2010), SE topics in the Lethbridge paper [P33], Synthesized } \\
\text { from literature, Synthesized from initial interview data, } \\
\text { Existing university courses, Other }\end{array}$ & $\mathrm{S}$ & SM \\
\hline 3 & Importance of SE skills & $\begin{array}{l}\text { Quantitative importance data for SE skills categorized using } 15 \\
\text { "knowledge areas" (KAs) of SWEBOK (Bourque and } \\
\text { Fairley, 2014): Requirements, design (and architecture), } \\
\text { development (programming), testing, maintenance, } \\
\text { configuration management, project management, SE process, } \\
\text { SE models and methods, quality, SE professional practice, SE } \\
\text { economics, computing foundations, engineering foundations, } \\
\text { and mathematical foundations }\end{array}$ & M & Meta-analysis \\
\hline 4 & $\begin{array}{l}\text { Knowledge gaps } \\
\text { (deficiencies) }\end{array}$ & $\begin{array}{l}\text { Quantitative knowledge gaps data for SE skills categorized } \\
\text { using } 15 \text { KAs of SWEBOK }\end{array}$ & M & Meta-analysis \\
\hline 5 & Soft skills & $\begin{array}{l}\text { Soft skill(s) deemed important, as mentioned in each paper: } \\
\text { Qualitative data (string) }\end{array}$ & M & $\begin{array}{l}\text { Qualitative } \\
\text { coding }\end{array}$ \\
\hline 6 & $\begin{array}{l}\text { Data sample } \\
\text { characteristics }\end{array}$ & $\begin{array}{l}\text { - Number of data points (participants, job advertisements): } \\
\text { integer } \\
\text { - Region (or country) the survey was conducted in: Name }\end{array}$ & M & SM \\
\hline 7 & $\begin{array}{l}\text { Educational } \\
\text { recommendations }\end{array}$ & $\begin{array}{l}\text { Educational recommendations as mentioned in each paper: } \\
\text { Qualitative data (string) }\end{array}$ & M & $\begin{array}{l}\text { Qualitative } \\
\text { coding }\end{array}$ \\
\hline 8 & \multicolumn{4}{|c|}{$\begin{array}{l}\text { No data from the primary studies are needed for this RQ since the RQ's goal is comparing our results to previous review } \\
\text { papers. }\end{array}$} \\
\hline
\end{tabular}

skills, we applied meta-analysis (Cruzes and Dyba, 2010) to extract and synthesize quantitative data from the primary studies.

For RQ 5 (important soft skills) and RQ 7 (educational recommendations), the data that we planned to extract were qualitative phrases from each paper. Given the nature of the extracted data for those two RQs, it was natural to choose qualitative coding (Miles et al., 2014) as our method of choice (Easterbrook et al., 2008). We will further discuss our meta-analysis and qualitative coding approaches in Section 5.3.

To derive the categories for all attributes/aspects in the systematic map (Table 2), we had in mind an initial list of categories. We then used attribute generalization and iterative refinement. If a category appeared in at least two papers, we included it as a separate category in the corresponding set, otherwise, we added it in the "Other" categories.

\subsection{Process for data extraction}

After developing the systematic map, each of the authors extracted data from the subset of the papers assigned to him. To ensure post-verification and quality of our data extraction activity, the authors recorded in their online data spreadsheet comments on each extracted data item pointing to the exact phrases/data in each primary study (a form of "traceability"). This made it easy and systematic to determine (and justify) why each classification was performed.

We also conducted systematic peer reviewing after the authors finished their data extraction. Each author peer-reviewed the data extraction of another author in the team. In the case of disagree- ments, further discussions took place to reach a consensus. Such discussions ensured the quality and validity of our results.

\subsection{Process for data synthesis and meta-analysis}

For two of the study's RQs (RQ 3 and RQ 4), we needed to conduct meta-analysis (Cruzes and Dyba, 2010; Miller, 2000; Glass, 1976) to synthesize and consolidate the quantitative data about the importance of SE skills, and knowledge gaps, as extracted from the primary studies. Meta-analysis is "a form of synthesis that combines the numerical results of primary studies" (Cruzes and Dyba, 2010). We consulted and carefully followed the guidelines for meta-analysis in SE (Cruzes and Dyba, 2010; Miller, 2000; Glass, 1976).

All papers had presented rankings for the most important skills and knowledge gaps. To be able to cross-compare and synthesize data in a consolidated manner, we harmonized those ranking data in our meta-analysis as follows.

We normalized the ranking of topics in each paper to the range of $[0,1]$, for each SWEBOK KA. For example, for [P1], three of the 13 ranked topics were related to the "design" KA: general architecture (in rank 1), object-oriented design (rank 9), and user-interface design (rank 12). We calculated the average of (1, 9, 12), which equals 7.33, and divided it by the number of all SE topics in that paper (13), and the normalized rank metric was 0.56 . We show in Fig. 4 the details for this example. We show a screenshot from the actual table in the primary study [P1] from which we extracted the data.

Note that since we used rank data, the lower the value of this metric, the higher the importance of a given topic. Thus, by calcu- 


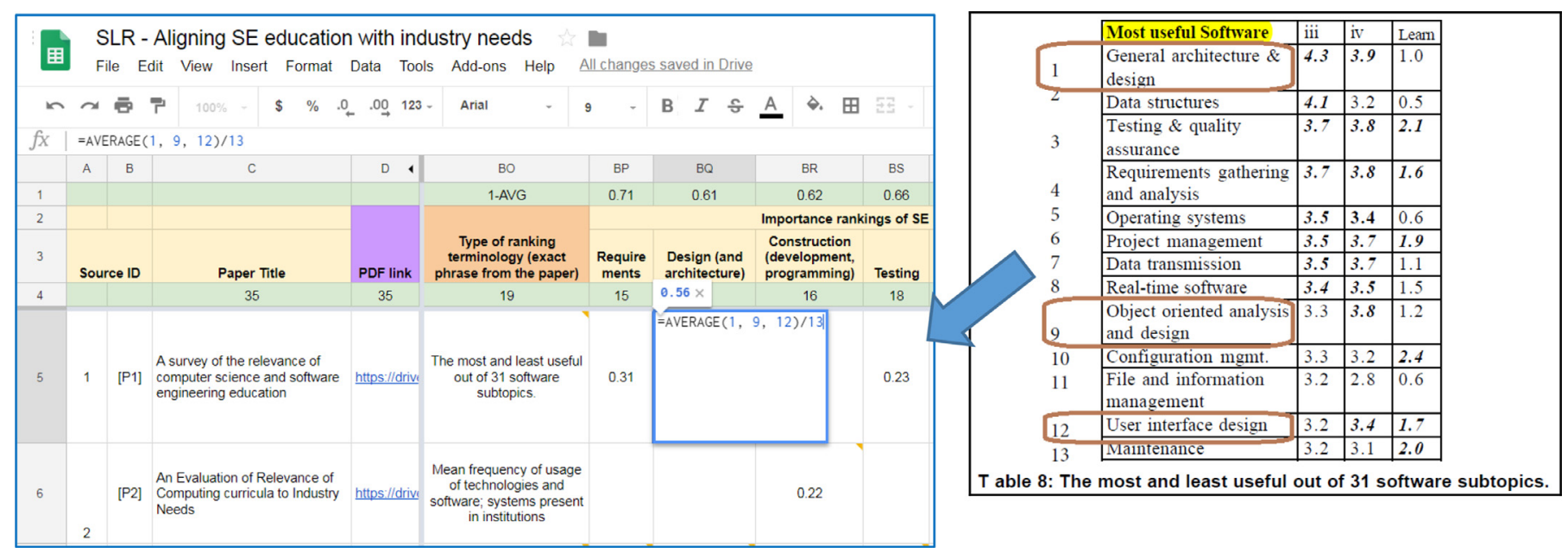

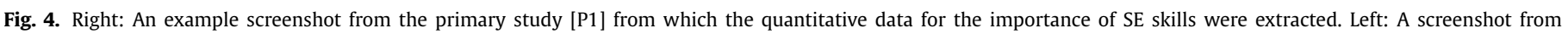
the data sheet showing an example of how we stored the data for each paper and consolidated all the data.

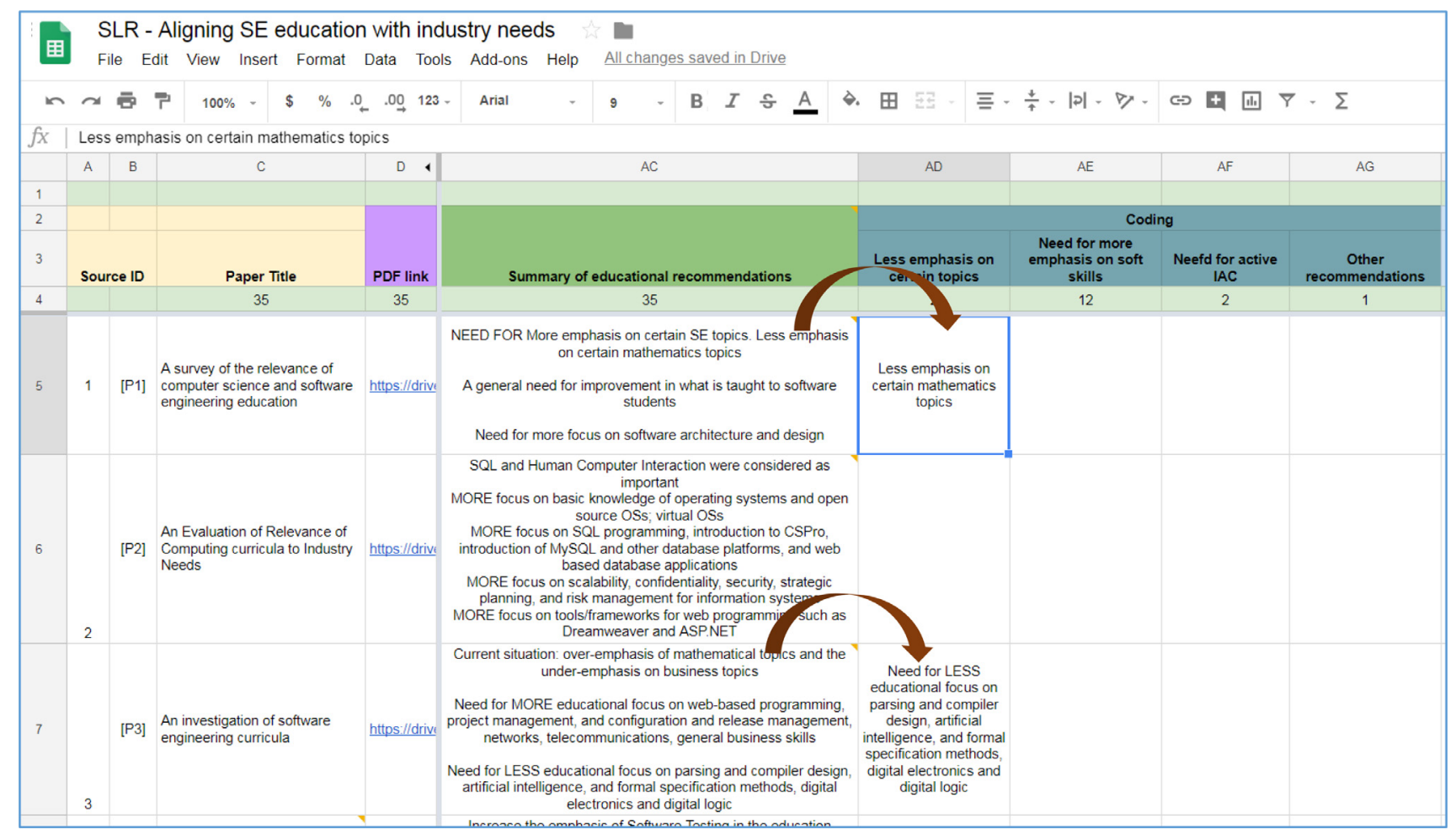

Fig. 5. A screenshot showing an example of how qualitative coding of educational recommendations was conducted.

lating "1- normalized rank", we aggregated the normalized importance $(=1-0.52=0.48$, for the above example paper). Once we had the importance metric value of each KA for each paper, we calculated its average among all papers.

Last but not the least, for RQ 5 (important soft skills) and RQ 7 (synthesis of educational recommendations), we used qualitative coding (Miles et al., 2014), which we have applied in several other recent SLR studies, e.g., (Garousi and Mäntylä, 2016; Garousi et al., 2017). We essentially took at each qualitative piece of data about educational recommendations, as extracted from each paper, and then performed "open" and "axial coding" (Miles et al., 2014). The creation of the new factors in the "coding" phase was an iterative and interactive process in which all five researchers participated. Fig. 5 shows a screenshot for an example of how we conducted qualitative coding of educational recommendations. We will dis- cuss more details and results of this process in Sections 6.5 and 6.7 .

\section{Results}

In this section, we present the results of the study's research questions (RQs).

\subsection{RQ 1: Types of data collection methods and metrics used}

We show in Fig. 6 the breakdowns of types of data collection methods and metrics used in the studies. 25 studies conducted opinion surveys to collect data from participants. Eight studies interviewed participants from both private and public sectors either face-to-face or via phone. [P16] formed "focus" groups to gather opinions via interviews. 


\begin{tabular}{|r|r|r|r|r|}
\hline & & \\
Opinion survey \\
Interviews
\end{tabular}

Fig. 6. Types of data collection methods (left) and metrics used (right).

Three studies [P16, P26, P35] mined job advertisements to explore skills desired by industry. For example, [P35] analyzed a set of 101 online job ads in the area of requirements engineering (RE) in the Netherlands to answer the question of: What the job market wants from requirements engineers?

Two studies used "other" data collection methods [P6, P29]. [P6] used a technique called "360-degree assessment" to provide a holistic view of employee skills in a multi-organizational study. Also known as 360-reviews or 360-degree employee-feedback, 360 -assessments provides a holistic view of a set of employees through a process of gathering feedback from an employee's manager, peers and direct reports (Seiler, 2005). [P29] reported the findings of an observational study of eight recent college graduates in their first six months of a software development position at Microsoft Corporation.

As for all empirical studies, the data collection methods used in the papers suffered from certain threats including coverage, nonresponse, and measurement errors (Groves, 2004). Many papers in the pool actually mentioned this explicitly. Coverage errors occur when the participants do not include some segments of the target population (Groves, 2004). All of the studies gathered data from a limited region with only alumni of one or a few universities. Moreover, some of the studies targeted specific SE roles, such as systems analysts, business analysts and project managers [P9], and realtime and embedded software developers [P1]. Some of the studies reported low response rates, e.g., [P1, P3, P4, P8], which can cause bias in the results.

Measurement errors arise when participants answer inaccurately due to the wording of questions, order of questions, interviewer effect, ${ }^{1}$ or other external factors (Groves, 2004). For instance, [P1] reported a possible difference between feeling and actual usefulness. Our meta-analysis study hopes at decreasing these threats by combining the results of all the studies.

In terms of the metrics used in the studies, as Fig. 8 illustrates, most of the studies (24 papers) quantified the importance of SE skills. Eight studies measured the knowledge gaps (skills required by industry, but which SE graduates do not possess sufficiently). Four studies measured how much SE graduates learned in university, two studies measured how much they know about SE topics, and two studies evaluated the usefulness of skills in industry. In most cases, these metrics were assessed using Likert scales. While all of the studies aimed to contribute to aligning SE education with industry needs in general, these metrics have been used to ad-

\footnotetext{
1 The interviewer effect (also called interviewer variance or interviewer error) is the distortion of response to a personal or telephone interview which results from differential reactions to the social style and personality of interviewers or to their presentation of particular questions (Groves, 2004) R. M. Groves, Survey errors and survey costs. John Wiley \& Sons, 2004.
}

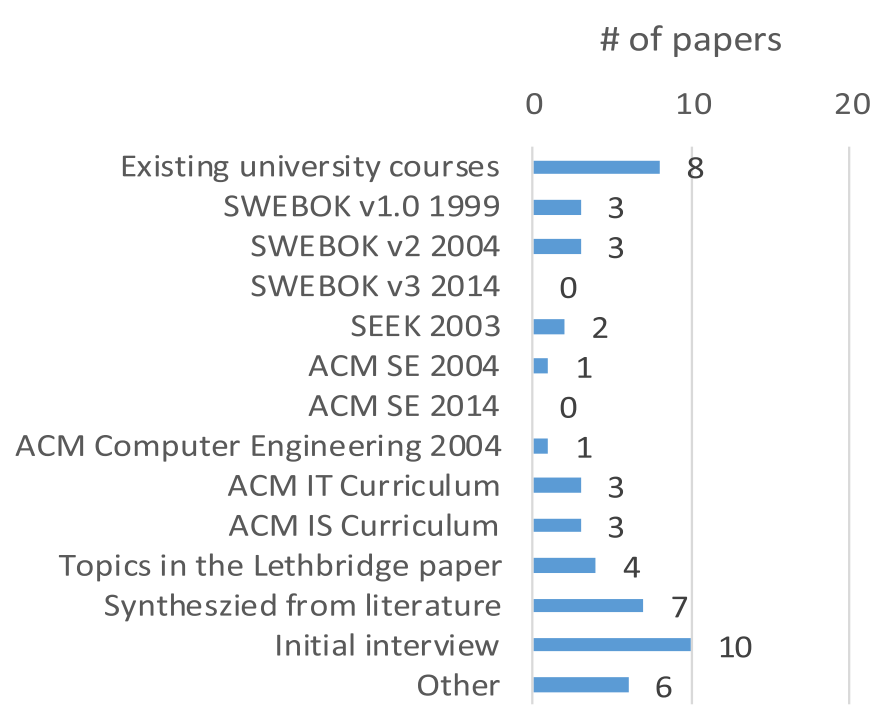

Fig. 7. Base models (bodies of knowledge) used for classification of SE topics.

dress various research questions. For example, [P6, P9] compared the importance of/deficiency in soft and hard skills. [P7] identified the importance of skills according to different positions. [P11, P12] reported on importance perception differences between employers and graduates.

6.2. RQ 2: Base models (bodies of knowledge) used for classification of SE topics

For classification of SE topics for the purpose of aligning them with industrial needs, studies used or proposed various classification models. The breakdown of those base models is shown in Fig. 7.

There have been many efforts towards classifying SE topics, which are often known as "bodies of knowledge". The Software Engineering Body of Knowledge (SWEBOK) is one of those community-based attempts for constructing a taxonomy of SE topics. Since the SE discipline is continuously evolving due to emerging new technologies and advances in practice, SWEBOK is regularly updated with new versions: its version \#1 was released in 1999 (Alain et al., 2001), version \#2 in 2004 (Alain et al., 2004), and version \#3 in 2014 (Bourque and Fairley, 2014).

Three studies [P1, P3, P33] used the topic taxonomy published in SWEBOK v1 and three [P4, P6, P14] using SWEBOK v2. None of the studies used SWEBOK v3, which is the most updated body of knowledge for SE. Our study fills this gap by re-classifying and 
combining all the skills reported in 35 studies based on SWEBOK v3.

In addition to SWEBOK, some other efforts have been made under the umbrella of $\mathrm{ACM} / \mathrm{IEEE}$ and have proposed guidelines for curriculum design, namely, the ACM "SE 2004" guideline (Institute for Electrical and Electronic Engineers (IEEE-CS) and Association for Computing Machinery (ACM) 2004) and "SE 2014" (Ardis et al., 2015), ACM Computer Engineering Curricula 2004 (Association for Computing Machinery (ACM) 2004) and 2016 (Association for Computing Machinery (ACM) 2016), ACM Computer Science Curricula 2013 (I. C. Society 2013), ACM IT curriculum 2017 (Sabin et al., 2015), and ACM IS curriculum 2010 (Topi et al., 2010). 10 studies, in total, used the classification of topics/skills from the above seven guidelines.

Initial interviews and synthesizing the topics from literature have been used in 10 and 7 studies, respectively. Eight studies used existing university courses, which carries a heavy risk of overlooking skills/topics required by industry and not addressed by existing university curriculum. Four studies used the SE topics presented in a highly-cited paper by Lethbridge [P33], which is one of the pioneering studies in aligning SE education with industrial needs.

Other SE topic lists have been obtained by mining job advertisements [P16, P26, P35], and using ABET accreditation (Accreditation Board for Engineering and Technology) (Accreditation Board for Engineering and Technology (ABET), 2019) [P19].

\subsection{RQ 3: Importance of SE skills}

When asking respondents to rate (rank) the importance of SE topics, different papers used different sets of SE topics (as discussed in the previous section) by using different bodies of knowledge. In other words, the questionnaires designed and used in the studies had differences w.r.t. the concrete SE topics used in them.

With such a diversity in the list of SE topics used in the studies, we selected the most relevant model, the latest version of SWE$\mathrm{BOK}$, version 3.0 and mapped the SE topics discussed in the papers to the 15 "knowledge areas" (KAs) of SWEBOK which are: requirements, design (and architecture), development (programming), testing, maintenance, configuration management, project management, SE process, SE models and methods, quality, SE professional practice, SE economics, computing foundations, engineering foundations, and mathematical foundations.

The next step was to consolidate the quantitative data of skill (topic) importance from all the papers. Almost all papers had presented the ranking of the most important skills. To be able to cross-compare and synthesize data in a consolidated manner, we harmonized the importance ranking data as follows. We normalized the ranking of topics in each paper to the range of $[0,1]$, for each SWEBOK KA. For example, for [P1], three of the 14 ranked topics were related to the "design" KA: general architecture (in rank 1), object-oriented design (rank 9), and user-interface design (rank 12). We calculated the average of (1, 9, 12), which equals 7.33, and divided it by the number of all SE topics in that paper (14), and the normalized rank metric was 0.52 . Note that since rank data were used, the lower the value of this metric, the higher the importance of a given topic. Thus, by calculating "1- normalized rank", we aggregated the normalized importance ( 0.48 for the above example). Once we had the importance metric value of each KA for each paper, we calculated its average among all papers.

Fig. 8 shows the most important topics in a scatter plot, in which the normalized importance metrics of each topic and the number of papers that it has appeared in, are shown. Given the fast-changing nature of the field of SE and the knowledge areas in it, we were curious to compare the skill importance data from all the papers, versus the papers published in the last five years. Thus, we calculated the above metrics for each case separately.
Comparison of the two charts in Fig. 8 provides interesting insights. When looking at all the papers, requirements, design and testing are the most important and most frequently-mentioned topics with SE professional practice, project management and development coming next. However, when looking at the recent papers, the top-3 topics change to SE professional practice, project management, and testing. This seems to denote that less technical skills such as SE professional practice and project management have become even more important in SE education in recent years. SE professional practice covers topics such as professionalism, group dynamics, and communication skills and these are (soft) skills especially required in modern agile software development that is more strongly based on communication and interaction than traditional waterfall approaches. According to our experience, an effective approach to cover project management and SE professional practice in our education practice is by larger SE projects done by student teams either in class or even together with companies (Garousi, 2011).

Mathematical and engineering foundations, as well as SE economics, are ranked low in both charts. This may highlight the establishment of SE (and its education) as a separate engineering discipline that relies on other sciences such as computer science, mathematics and economics and adopting ideas from those subjects by developing new approaches to solve problems in engineering software (Briand, 2012). In line with this finding, it is interesting to observe that requirements, testing, and design are considered more important than the actual development. However, according to our experience, this is not always reflected in SE education, especially if it is embedded into computer science curricula.

In addition, it is interesting to observe that there are weak to moderate correlations in the two charts in Fig. 8. The Pearson correlation coefficients are 0.63 (top plot) and 0.34 (bottom plot). Thus, it is the case that when a SE topic has appeared in more papers in the pool, the average importance may be higher.

\section{4. $R Q$ 4: Knowledge gaps (deficiencies)}

Eight (8) of the 35 studies measured, in quantitative terms, the knowledge gap (deficiency) from their survey participants, which was usually done by subtracting the importance-in-job measure of a given SE topic from the measure of how much the participant had learned during her/his university education. We extracted all that quantitative knowledge gap values and calculated their normalized average. We show in Fig. 9 two scatter plots to visualize the average knowledge gap values versus their importance. Similar to the previous Fig. 8, we show two charts for two cases: (1) all the eight studies reporting knowledge gaps, and (2) six of those eight papers which have been published in the last five years. The X-axis shows the average importance and the Y-axis the average knowledge gap. As we can see, in the case of all eight papers, generally speaking, the two factors are quite correlated and with increasing reported importance, more knowledge gap has been reported. The greatest reported knowledge gaps are in the following areas: (1) configuration management, (2) SE models and methods, (3) SE process, (4) design (and architecture), and (5) testing. Thus, in general, more education and training focus shall be given to these topics, by university programs and when training newly-hired staff in the industry.

When we look at the recent data (the last five years), the difference w.r.t. both metrics are more widespread and thus it is easier to differentiate and pick the topics with the highest knowledge gaps. We have divided the scatter plots of Fig. 9 into four quadrants to be able to clearly see the SE topics with low/high importance and low/high knowledge gap.

Topics in Q1 (high importance, high gap) are those which need the highest attention w.r.t. need for improvements in SE educa- 


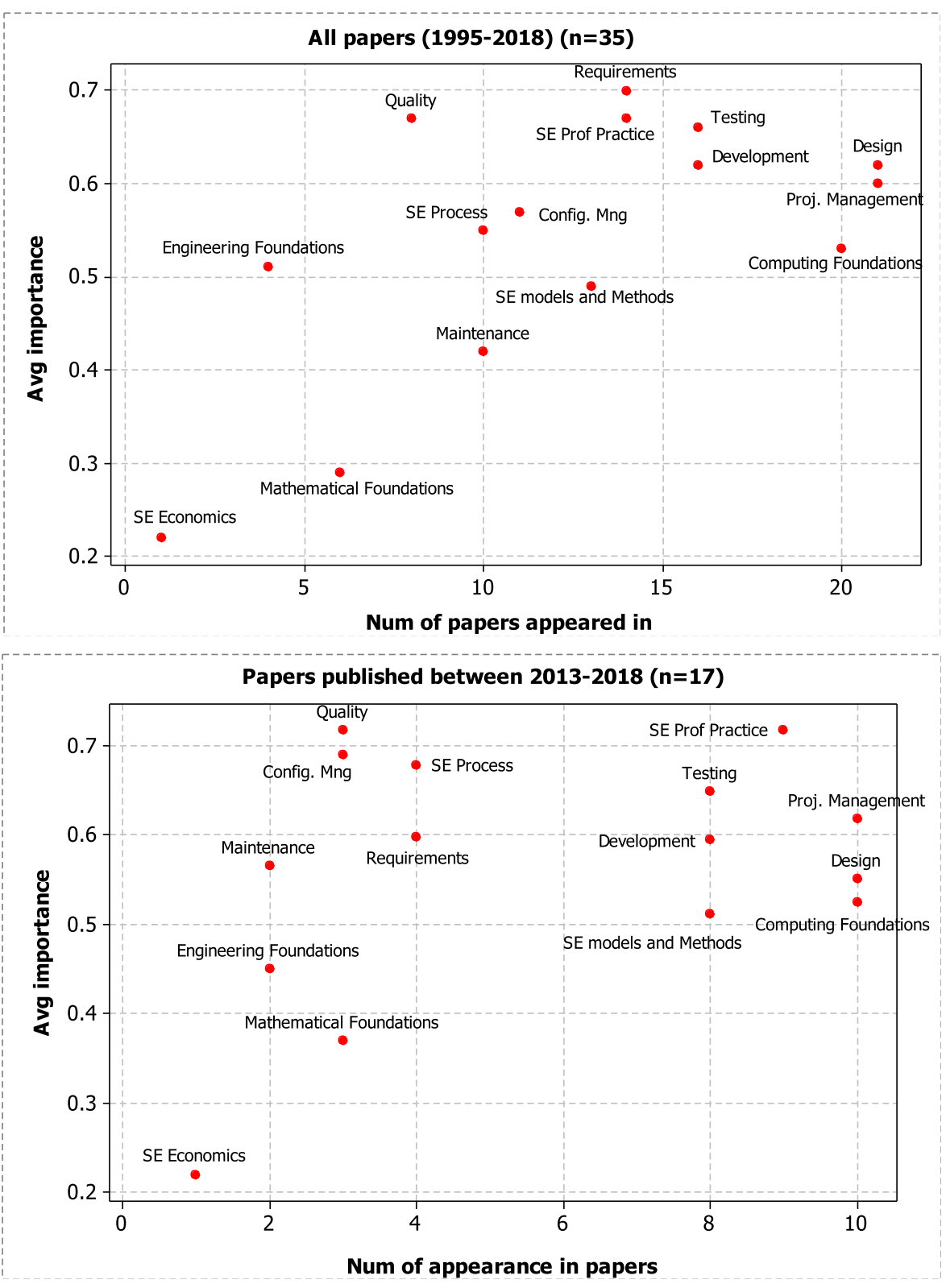

Fig. 8. The most important skills (data from all the papers, versus papers in the last five years).

tion in university programs. They have high importance, but high knowledge gap. Topics in Q2 (low importance, high gap) should get the next level of attention w.r.t. SE education (after those in Q1). They have relatively low importance, but there are still high knowledge gaps in those topics, and thus need for more education and training on those topics.

In terms of topics in Q3 (high importance, low gap), the university programs are generally doing a good job, since knowledge gaps in those topics are relatively low, while they are quite important w.r.t technical needs in the industry. Only the software "development" topic slightly falls in Q3 in one of the scatter plots in Fig. 9.

Topics in Q4 have low importance, and low knowledge gap, thus they are the least critical w.r.t. need for improvements and attention of SE education in university programs. The KA "Mathematical foundations" falls into Q4 in both scatter plots.

\section{5. $R Q$ 5: Importance of soft skills}

It is widely discussed in the community that hard (technical) skills alone do not make a great software engineer (Li et al., 2015) and soft skills are equally important (if not more). Hard skills are comprised of domain knowledge and technical skills, while soft skills are comprised of the team and interpersonal skills. "Soft skills contribute significantly to individual learning, team performance, client relations and awareness of the business context" [P16].

As discussed in Section 5.3, to synthesize data for this RQ, we used qualitative coding (Miles et al., 2014). While extracting the raw data from the primary studies (soft skills deemed important), we noticed that a large variety of soft skill phrases were mentioned in the papers, and presenting them all in our SLR would, in their "raw" form, lead to an outcome which could look raw and un-synthesized. By following qualitative coding (Miles et al., 2014), groups of soft skills emerged as we synthesized the data. 

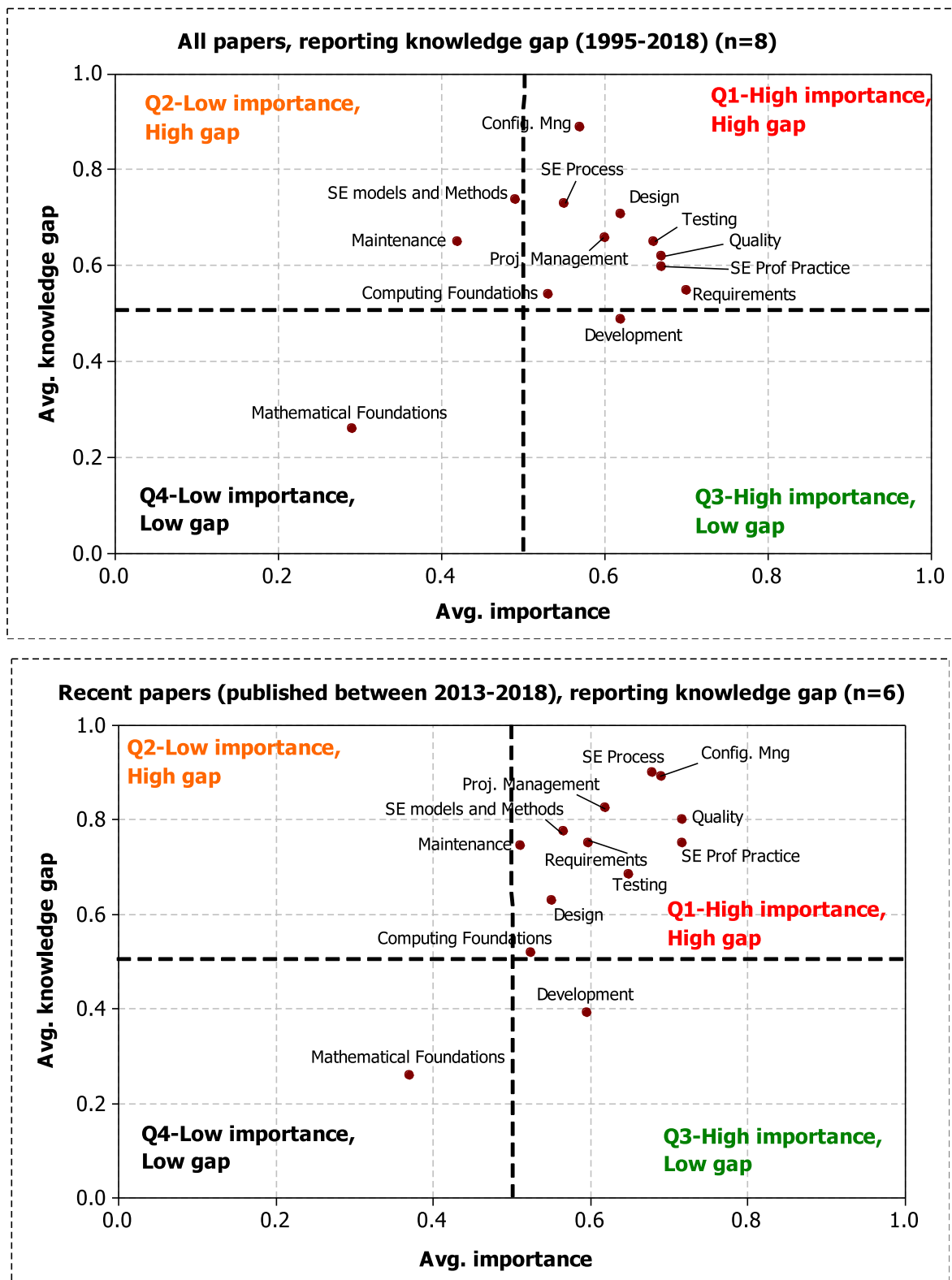

Fig. 9. Topics with the greatest knowledge gap-where importance exceeds current knowledge of survey participants.

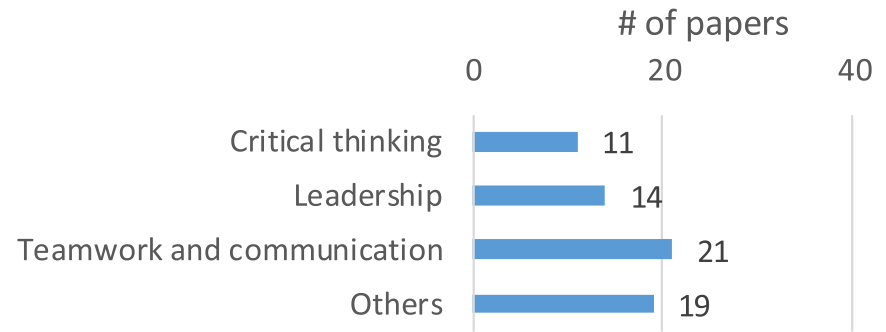

Fig. 10. Importance of soft skills as discussed in the papers.

As a result of qualitative coding, we categorized the soft skills as shown in Fig. 10: Teamwork and communication (discussed in 21 studies), Leadership (14 studies), Critical thinking (11 studies) and Others (19 studies). Many other important soft skills have been mentioned in the papers, such as cultural fit, understand business drives, aptitude, attitude, coping with ambiguity, learning and curiosity, and passion/drive to innovate.

Some studies even reported quite bold findings, e.g., survey data of an American study [P9] showed that "soft skills are significantly more important than hard skills for entry-level positions". A study performed in New Zealand [P5] reported that: "Soft skills are critical skills in SE and make up seven of the top eight most important skills [in that study]". [P23] also recommended that: "Soft skills and business skills must be included in curricula".

These statements are in line with the finding that SE professional practice is of high importance (see Fig. 8) which comprises of topics such as professionalism, group dynamics, and communication skills.

\section{6. $R Q$ 6: Data sample characteristics}

In terms of the number of data points (respondents of surveys), studies had between eight [P28] and 600 respondents [P21]. We show in Fig. 11 the histogram of the number of data points in each 


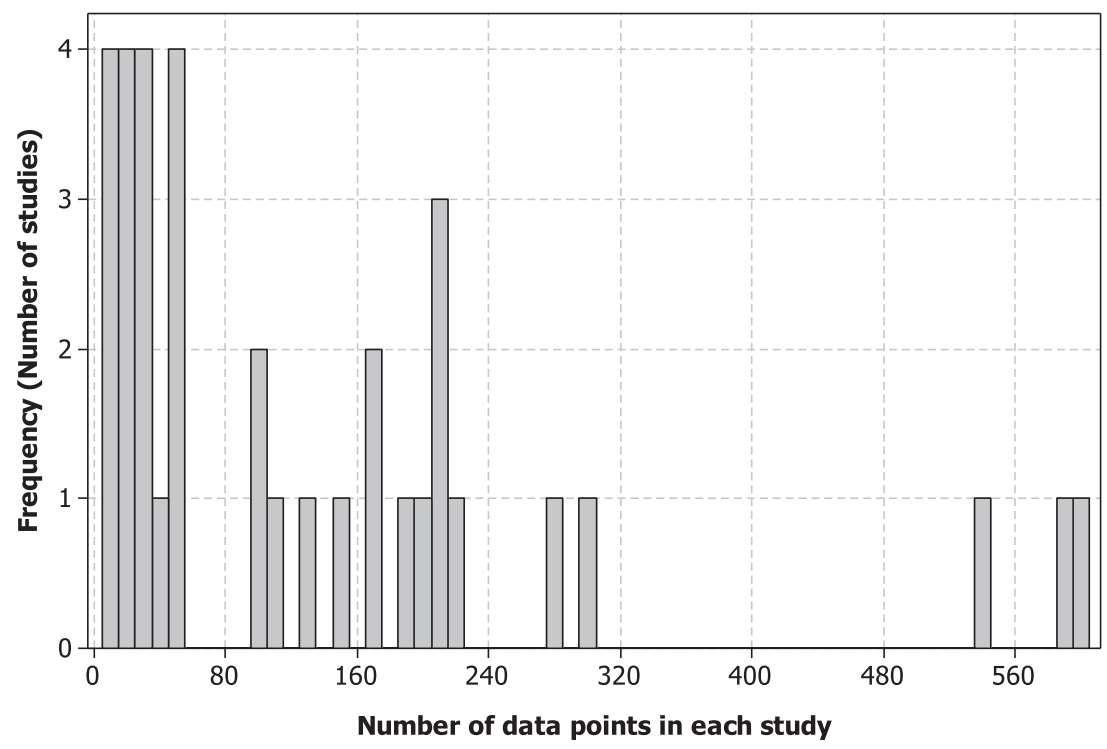

Fig. 11. Histogram of the number of data points in each study.

Table 3

List of countries w.r.t. where the data have been gathered from.

\begin{tabular}{lll}
\hline Countries & Num. of studies & Study references \\
\hline USA & 16 & {$[\mathrm{P} 1, \mathrm{P} 7, \mathrm{P} 8, \mathrm{P} 9, \mathrm{P} 10, \mathrm{P} 11, \mathrm{P} 13, \mathrm{P} 15, \mathrm{P} 18, \mathrm{P} 19, \mathrm{P} 20, \mathrm{P} 21, \mathrm{P} 22, \mathrm{P} 24, \mathrm{P} 29, \mathrm{P} 33]$} \\
Canada & 4 & {$[\mathrm{P} 1, \mathrm{P} 31, \mathrm{P} 32, \mathrm{P} 33]$} \\
South Africa & 4 & {$[\mathrm{P} 17, \mathrm{P} 23, \mathrm{P} 28, \mathrm{P} 30]$} \\
New Zealand & 2 & {$[\mathrm{P} 5, \mathrm{P} 16]$} \\
Spain & 2 & {$[\mathrm{P} 6, \mathrm{P} 14]$} \\
Samoa & 1 & {$[\mathrm{P} 2]$} \\
England & 1 & {$[\mathrm{P} 3]$} \\
Norway & 1 & {$[\mathrm{P} 4]$} \\
Philippines & 1 & {$[\mathrm{P} 12]$} \\
Jordan & 1 & {$[\mathrm{P} 26]$} \\
Netherlands & 1 & {$[\mathrm{P} 35]$} \\
Australia & 1 & {$[\mathrm{P} 27]$} \\
Finland & 1 & {$[\mathrm{P} 34]$} \\
Worldwide & 1 & {$[\mathrm{P} 25]$} \\
\hline
\end{tabular}

study. Three studies had participants between 543 and 600 [P16, P21, P22], whereas the rest had less than 300 data points.

Since the studies were mostly conducted in different countries, there is a small chance that a single software engineer had participated in more than one study in the pool. Thus, when we add up the number of respondents from all 35 studies, we can say that the data and evidence are from "up to" 4,132 respondents. By combining data and evidence from all previous studies and by having such a large combined dataset, our study aims to provide a more comprehensive view of the topic.

Furthermore, we show in Table 3 the list of countries where the data have been gathered from and also the study references. The top countries from which data were gathered were: USA (16 papers), Canada (4), South Africa (4), New Zealand (2) and Spain (2). Each of the following countries was represented in one paper each: England, Norway, Philippines, Jordan, Australia, Finland and Samoa. Two papers had data from both the USA and Canada [P31, P33] and one paper surveyed data from all over the world [P25]. The advantage of our meta-synthesis (meta-analysis) is that the combined dataset has data from 13 countries which provides a stronger evidence on the subject.

At the same time, Table 3 shows a strong bias of the combined (synthesized) data-set towards North America. More than half of the studies (20 out of 35 ) have been conducted in the US and Canada, respectively, which means the results might not be applicable in other countries, i.e., in particular some countries in Europe but also India and China are missing. Thus, the results of the study should be interpreted carefully and treated with "a grain of salt". We have added a discussion in the threats to validity, about this issue.

\section{7. $R Q$ 7: Synthesis of educational recommendations}

To answer RQ 7, we looked for common and interrelated themes to build a holistic view on aligning SE education with industry needs. To achieve this, we used qualitative coding (Miles et al., 2014).

Application of qualitative coding provided four themes for the educational recommendations provided in the papers, as shown in Fig. 12:(1) Need for more emphasis on soft skills (20 papers), (2) Need for active IAC (3 papers), (3) Less emphasis on certain topics (2 papers), and (4) Other recommendations (7 papers). Note that we intentionally did not create a group for "More emphasis on certain topics" since such recommendations are obviously provided in all the papers, given the scope of our review.

Soft skills are important for software engineers since SE activities are carried out in a social context that is made up of people with different personalities. As being a part of such a social context, software engineers should possess some soft skills to fulfill their responsibilities. 20 of the 35 studies emphasized the importance of soft skills and identified a need for improving students' soft skills during university education. [P7] and [P9] reported that 


\section{\# of papers}

0

20

40

Need for more emphasis on soft skills

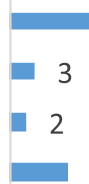

20

Less emphasis on certain topics

Other recommendations

7

Fig. 12. Qualitative coding of educational recommendations, presented in the papers.

soft skills are even more valued by industry than hard skills. The rationale behind this is that soft skills are not directly teachable and requires extensive effort and time to improve compared to hard skills (Bereiter and Scardamalia, 2006). [P7] and [P22] also pointed out the increasing importance of soft skills in parallel with an increase in the level of position in an organization. Hard skills are more important for entry-level positions [P7, P22], whereas soft skills are becoming more important at higher levels. Such a recommendation has also been supported by studies outside SE, e.g., (Katz, 2009), which mentioned that, in higher position levels, managers' effectiveness depends largely on soft skills.

To provide SE students a setting for improving soft skills as well as applying hard skills, it is suggested to use real-life projects, e.g., [P20, P23, P26, P27, P28], which emphasized the importance of internships and real-life projects as a part of formal SE education. [P28] reported that "Real-life and practical experience must be included in students' education". [P27] also highlighted the need for "more exposure to real life, exercises, team assignments or industry projects". Such complementary activities enable students to participate in the learning process actively and hence provide them with an environment for improving soft and hard skills [P27]. On the other hand, these benefits do not come for free. Instructors should envisage the effort for planning, running, and coordinating such activities [P26]. Moreover, when a part or all of these activities need the participation of stakeholders from industry, a proper setting should be established for industry-academia collaboration (Garousi et al., 2016). Besides providing real-life projects, the industry can also support academia in developing curriculum [P12, P28] and also in delivering some lectures [P26].

Another important point to be raised is keeping SE curriculum continually up-to-date (Boehm, 2006). As Boehm stated, it is important to "anticipate future trends, prepare students to deal with them, monitor current principles and practices and separate timeless principles from out-of-date practices" (Boehm, 2006). In parallel with this, [P1, P28] emphasized the need for curriculum change based on inputs from industry. Aligned with curriculum updates, lecturers/educators should also adapt themselves to the changes in the SE field [P30].

We also observed many other interesting findings when reviewing the papers. For example, there were suggestions on decreasing emphasis on certain topics in SE university education (i.e., what we should teach less). [P1] expressed that "Participants felt that their university education gave them a much better grounding in mathematics than in software topics", and thus recommended that: "emphasis on certain mathematics topics should be changed [decreased]". The empirical data also showed that "much mathematics is being forgotten, whereas much new software knowledge is being acquired on-the-job". [P3] also reported that there is "over-emphasis on mathematical topics and under-emphasis on business topics" in SE education. [P3] called for a less educational focus on parsing and compiler design, formal specification methods, digital electronics and digital logic in SE programs.
Several interesting suggestions were also made in [P29], e.g., about benefits of working with existing code-bases: "Instead of a greenfield project, a more valuable experience would provide students a large pre-existing codebase to which they must fix bugs (injected or real) and write additional features". [P29] also suggested to include training about management skills as it said: "Also valuable would be a management component, where students must interact with more experienced colleagues (students who have taken the class previously, who can act as mentors) or project managers (teaching assistants) who teach them about the codebase".

\section{8. $R Q$ 8: Comparing our results to previous review papers}

As discussed in Section 2, the RQs of three related survey papers (Radermacher, 2012; Radermacher and Walia, 2013; Aničić et al., 2017) have similarities to our RQs. We provide a comparison of findings w.r.t. to those RQs from those studies with our findings in Table 4.

In Aničić et al. (2017), the authors performed a meta-analysis of the 155 papers in the ICT area. The RQs of that study were broader and concentrated on clustering the range of topics as follows: curriculum design and delivery, mismatch between learning outcomes of ICT graduates and skills requirements from the labor market, different/new teaching assessment methods in the education of ICT professionals, improvement in collaboration between ICT academics and ICT practitioners, and employability of ICT graduates. Based on these clusters, the authors compiled a list of educational recommendations from the analyzed papers. According to the study, while a considerable number of papers describe challenges and bottlenecks in education and careers of ICT professionals; only a few papers identify and justify new approaches for proposing solutions to challenges in ICT education and ICT career development. The main recommendation of the paper was to position student employability as the key metric for universities.

Another study (Radermacher and Walia, 2013) presented a literature review on exploring the areas where graduating students most frequently fall short of the expectations of industry. The main findings of the results indicated that the graduating students are lacking in both technical abilities (design, testing, configuration management tools etc.) and personal skills (oral and written communication, teamwork, etc.). The authors analyzed the trends of knowledge deficiencies of students over time. The authors counted the number of occurrences where a knowledge deficiency is mentioned in the primary studies rather than ranking them.

The other study (Radermacher, 2012) is a Master's thesis by the first author of Radermacher and Walia (2013). By being slightly different than Radermacher and Walia (2013), the study provided the trends of knowledge deficiencies over the years which could be potentially valuable. The other significant difference is that the study provided an overview of knowledge deficiencies across different perspectives (managers, new hires, experienced employees, and students). It was found worthwhile to compare the viewpoints of different roles on this issue.

\section{Discussion}

We discuss next some of the possible benefits of this review (Section 7.1) and then we discuss potential threats to validity of this review (Section 7.2) and the steps that we have taken to mitigate or minimize them.

\subsection{Potential benefits of this review}

We discuss next the potential benefits of our SLR for educators, researchers, hiring managers and students.

Benefits for educators and researchers: 
Table 4

Comparison with other related literature review papers.

\begin{tabular}{|c|c|c|c|c|}
\hline \multirow{3}{*}{$\begin{array}{l}\text { Criteria } \\
\text { Literature review period }\end{array}$} & \multicolumn{4}{|c|}{ Related literature review paper } \\
\hline & (Radermacher, 2012) & $\begin{array}{l}\text { (Radermacher and } \\
\text { Walia, 2013) }\end{array}$ & (Aničić et al., 2017) & This study \\
\hline & $1995-2012$ & 1995-2013 & 1980-2014 & $1995-2018$ \\
\hline $\begin{array}{l}\text { Top knowledge deficiencies } \\
\text { identified (technical) }\end{array}$ & $\begin{array}{l}\text { Testing, programming, } \\
\text { project management }\end{array}$ & $\begin{array}{l}\text { Design, testing, } \\
\text { configuration } \\
\text { management tools }\end{array}$ & - (not reported) & $\begin{array}{l}\text { Configuration management, SE } \\
\text { models and methods, design }\end{array}$ \\
\hline $\begin{array}{l}\text { Top knowledge deficiencies } \\
\text { identified (soft skills) }\end{array}$ & $\begin{array}{l}\text { Teamwork, oral } \\
\text { communication, } \\
\text { problem solving }\end{array}$ & $\begin{array}{l}\text { Oral and written } \\
\text { communication } \\
\text { teamwork } \\
\text { ethics }\end{array}$ & - & $\begin{array}{l}\text { Critical thinking, leadership, } \\
\text { teamwork, and communication }\end{array}$ \\
\hline $\begin{array}{l}\text { Ranking mechanism of } \\
\text { knowledge deficiencies }\end{array}$ & $\begin{array}{l}\text { Counting the number } \\
\text { of occurrences of the } \\
\text { deficiencies }\end{array}$ & $\begin{array}{l}\text { Counting the number } \\
\text { of occurrences of the } \\
\text { deficiencies }\end{array}$ & - & $\begin{array}{l}\text { Relative ranking provided by } \\
\text { the papers }\end{array}$ \\
\hline $\begin{array}{l}\text { Change in knowledge } \\
\text { deficiencies over time }\end{array}$ & $\begin{array}{l}\text { Trends were provided } \\
\text { per each knowledge } \\
\text { area }\end{array}$ & - & - & $\begin{array}{l}\text { Overall and last } 5 \text {-years results } \\
\text { were compared }\end{array}$ \\
\hline $\begin{array}{l}\text { Taxonomy used for } \\
\text { classification of knowledge } \\
\text { deficiencies }\end{array}$ & $\begin{array}{l}\text { Authors' own } \\
\text { classification }\end{array}$ & $\begin{array}{l}\text { Authors' own } \\
\text { classification }\end{array}$ & - & SWEBOK v3 \\
\hline Importance of skills & - & - & - & $\begin{array}{l}\text { Importance of skills is provided } \\
\text { if found in the primary paper. }\end{array}$ \\
\hline $\begin{array}{l}\text { Synthesis of educational } \\
\text { recommendations }\end{array}$ & - & - & $\begin{array}{l}\text { List of educational } \\
\text { recommendations } \\
\text { classified into key areas }\end{array}$ & $\begin{array}{l}\text { List of educational } \\
\text { recommendations classified } \\
\text { according to different } \\
\text { stakeholders }\end{array}$ \\
\hline $\begin{array}{l}\text { Description of data sample } \\
\text { characteristics (as discussed in } \\
\text { our RQ 6) }\end{array}$ & - & Not explicitly provided & Not explicitly provided & Explicitly provided \\
\hline Targeted industry role & $\begin{array}{l}\text { Software engineers/ } \\
\text { developers }\end{array}$ & $\begin{array}{l}\text { Software engineers/ } \\
\text { developers }\end{array}$ & ICT professionals & Software engineers/ developers \\
\hline
\end{tabular}

- Adapting university curricula based on industry's needs: The information we have provided in RQ 3 (Importance of SE skills), RQ 4 (Knowledge gaps) and RQ7 (synthesis of educational requirements) could be used by educators to address the knowledge deficiencies in SE and improve their curricula.

o For example, among our findings was that, when looking at the recent papers, the top-3 most important SE skills are SE professional practice, project management, and testing. This seems to denote that skills such as SE professional practice and project management (which used to be less important) have become more important in industry in recent years. SE professional practice covers topics such as professionalism, group dynamics, and communication skills and these are (soft) skills especially required in modern agile software development.

- We found that the greatest knowledge gaps are in the following areas: (1) configuration management, (2) SE models and methods, (3) SE process, (4) design (and architecture), and (5) testing. Thus, in general, more education and training focus shall be given to these topics, by university programs and SE educators.

- Future education research on the topic: This SLR can be a valuable resource for future research on knowledge deficiencies and their importance by providing researchers with a structured roadmap. We provide our concrete suggestions below:

- Furthermore, while we developed a suitable approach (see Section 5.2) to extract and then synthesize the relative ranking data from the primary studies, it would be a good idea to have an established survey "protocol" (perhaps based on SWEBOK) which future primary studies (opinion surveys about knowledge gaps) could use to replicate surveys. When (and if) established and used by many future survey studies, such a "uniform" survey protocol could facilitate cross comparisons and future meta-analysis studies like this work.

- We also think future education research could look into the "challenges" of aligning SE education with industrial needs. While perhaps many SE educators are possibly aware of SE areas with high knowledge gaps in industry, what are the issues in curriculum and university contexts which make it challenging to better align SE education w.r.t. those knowledge gaps?

- We saw in Section 6.6 that about half of the studies extracted data in the US (16 of 35 papers). Also several other "clusters" of studies were reported for a few other countries, such as Canada. Further research could conduct metaanalysis on such sub-datasets only, to provide regional insights.

Benefits for hiring managers:

- Addressing the knowledge deficiencies: The reported knowledge deficiencies from the literature that we have summarized in RQ3, RQ4, and RQ5 could potentially be used by the industry when designing an onboarding program for new hires. For example, the proposed onboard training program would focus on certain topics to address the knowledge deficiencies. In the context of a large software company in Turkey, with which one of the authors was affiliated with, an industrial training program for potential new hires was recently conducted (Tuzun et al., 2018) based on the insights provided by this review study.

- Calibrating the expectations and interview process of new hires: This study provides an overview of expected capabilities of new hire student population in different dimensions. Based on this data, the hiring manager would have a general 
expectation of a new hire and could potentially change their expectations for a new hire and the interview process.

- Assessing employee competencies and deciding for new hires: The organization should support the current project groups with the missing expertise and therefore, the output of this study can help managers to observe the neglected roles in the organization and find new hires for these missing competencies required.

Benefits for students:

- Addressing their knowledge gaps: The reported knowledge deficiencies from the literature that we have summarized in RQ3, RQ4, and RQ5 could potentially be used by the students to address the gap by themselves. This reported knowledge deficiencies could be addressed via different methods such as MOOCs (Massive Open Online Courses), certificate programs, self-study, and internships. Students can learn the important skills required for the software industry before applying for and starting SE positions. While doing a side project that the student is passionate about, the student can improve her/his skills by considering the skills emphasized in this study.

\subsection{Potential threats to validity}

We carefully identified and addressed potential threats to validity in each step of the study. We followed the guidelines for performing systematic literature reviews and benefited from our previous experience, e.g., (Garousi et al., 2016; Doğan et al., 2014). This sub-section discusses the potential threats to validity and the actions we took to minimize or mitigate them.

\subsubsection{Internal validity}

A systematic approach has been applied to conduct this study, as described in Sections 3-5. To enable the repeatability of this study, we have defined and reported all the steps, including search engines, search terms, inclusion/exclusion criteria used. Some problems related to internal validity might have occurred due to the limitation of search engines and terms and bias in applying inclusion/exclusion criteria.

To have a finite set of primary studies for review, it is mandatory to limit the search engines and terms used. Such a limitation is a threat for the completeness. To decrease the possible negative impact of this risk, all the authors conducted independent searches using the search terms. In addition, we also conducted forward and backward snowballing (Wohlin, 2014) on the set of papers already in the pool.

To minimize the risk of bias in applying inclusion/exclusion criteria, authors voted for the papers to be included. The papers which had conflicting votes have been explicitly discussed by the authors. A consensus has been reached for all of such papers.

\subsubsection{Construct validity}

The suitability of RQs and categorization scheme used for data extraction address the construct validity for this study. We believe that with a suitable list of RQs and a good design of the categorization scheme in the way that it would better relate to the theoretical concepts behind this study, this study would have higher construct validity.

We thoroughly examined the related work and extracted RQs and a categorization scheme based on the current literature. The RQs cover our research goals, which have been answered according to the categorization scheme. Moreover, peer reviews were performed to increase the quality of data extracted.

\subsubsection{Conclusion validity}

To be able to provide scientific conclusions, it is mandatory to treat the primary studies rigorously and in a repeatable manner. We treated all the papers we could have reached through a carefully designed and executed search process. The authors refined the categorization scheme iteratively to avoid any ambiguity. Peer review has mitigated the risk of bias in data extraction and disagreements have been resolved by consensus. Our well-defined, executed and reported research method ensures the replicability of this study without major differences in the conclusions.

Another issue w.r.t. our meta-analysis is due to the data gathered in primary studies, which applied different data collection methods. As discussed in Section 6.1, most studies have used opinion surveys, while some have used interviews, or data from mining job advertisements. According to the guidelines for meta-analysis in SE (Cruzes and Dyba, 2010; Miller, 2000; Glass, 1976), we did not see any major issue when aggregating data from these multiple sources. It is actually common in Empirical SE to gather data from different sources and with different data collection methods (Cruzes and Dyba, 2010; Miller, 2000; Glass, 1976), and it would be a form of multi-method (or mixed method) approach.

Related to the above possible issue, is the fact that different primary studies have used different base knowledge models (as discussed in Section 6.2). As discussed in Section 6.3, we harmonized the ranking data for SE skills w.r.t. different knowledge models by classifying the SE topics in each of the primary studies under knowledge areas of SWEBOK. We believe this data harmonization approach was a sound and reasonable practice and we observed that the classification went smoothly.

Let us recall from Section 6.6 that our meta-analysis aggregated the data from a set of primary studies stemming from 13 countries, and we are aware that, we in no way assume a similar reality for the software industry and the SE education in different countries. In any country, the software industry needs and the SE education are influenced by a set of context variables (usually related to the local reality) such as maturity level of the software industry (including the stakeholders), type of software products developed in the region (e.g., embedded systems or games), socioeconomic conditions, level of IT adoption, etc. Let us also recall from Section 6.6 that when we added up the number of respondents from all 35 studies, the combined dataset included 4,132 data points (respondents). Thus, our meta-analysis is similar to a large-scale survey which would have received that many data points from the 13 countries listed, and we know that many such opinion survey studies (covering many countries) are regularly reported in SE and their findings are considered valuable. Furthermore, about half of the studies collected data in the US (16 of 35 papers). Thus, further research could conduct meta-analysis of such datasets only, to provide regional insights.

\subsubsection{External validity}

External validity is defined as to what extent the results of this study can be generalized. We extracted data from all studies in the relevant literature, which provided sufficient information.

However, as discussed in Section 6.6, we observed a strong bias of the combined (synthesized) data-set towards North America. We saw that more than half of the studies (20 out of 35 ) have been conducted in the US and in Canada, which means the results might not be applicable in other countries, i.e., in particular some European countries and also India and China are missing. Thus, the results of the study should be interpreted careful and treated with "a grain of salt". In addition, the focus of the studies lies on traditional universities, which have a quite similar educational canon all over the world. However, the generalizability to other tertiary education institutes like colleges, polytechnic universities or universities of applied sciences may be limited. 


\section{Conclusion and future work}

The findings presented in this article show the importance of SE professional practice and soft skills in general, the importance of certain areas in SE education (especially requirements, design and testing), knowledge gaps in specific areas of SE (especially configuration management, SE models and methods as well as SE process), and the importance of real-world examples in SE courses.

The authors have already started to benefit from the findings of the presented review and meta-analysis study in their SE education activities in several ways. This review has helped us to identify the most important SE topics, based on the largest synthesized body of evidence in the literature. Also, we found that the greatest knowledge gaps are in configuration management, SE models and methods, SE process, design (and architecture), and testing. Furthermore, in our ongoing university SE courses, we have started to align our teaching materials with the important topics and areas which have the greatest knowledge gaps. Also in the context of a large software company in Turkey, with which one of the authors was affiliated with, an industrial training program for potential new hires was recently conducted (Tuzun et al., 2018) based on the insights provided by this review study. We are certain that the results and findings presented in this paper will also benefit other educators and hiring managers by helping them adapt their education/hiring efforts to best prepare the SE workforce.

Finally, the findings also show that mathematical and engineering foundations are often overemphasized in SE programs. This highlights the need to further establish SE as a separate engineering discipline using knowledge from computer science and other basic sciences such as mathematics, economics or even psychology, and to further separate computer science from SE university programs (Parnas, 1999). This literature review can serve as a starting point for future research into knowledge deficiencies and their importance by proving researchers with a structured roadmap, and existing knowledge deficiencies.

Our future work will include (1) performing a recent survey on this topic; (2) assessing a set of SE programs in several universities based on the results of this study; and (3) conducting interviews with software companies to get their feedback about our empirical results.

\section{References}

This section is divided into two parts: (1) Citations to the primary studies reviewed in the SLR; and (2) Other (regular) references cited throughout the paper.

Primary studies (sources reviewed in the SLR)

[P1] T. C. Lethbridge, "A survey of the relevance of computer science and software engineering education," in Conference on Software Engineering Education, 1998, pp. 56-66.

[P2] I. C. Mow, H. Sasa, F. Maua-Faamau, E. Mauai, M. Tanielu, "An Evaluation of Relevance of Computing curricula to Industry Needs", in Systemics, Cybernetics and Informatics, vol. 13, no. 1, pp. 7-12, 2015.

[P3] B. Kitchenham, D. Budgen, P. Brereton, P. Woodall, "An investigation of software engineering curricula," Journal of Systems and Software, vol. 74, no. 3, pp. 325-335, 2005.

[P4] A. Deak, G. Sindre, "Analyzing the importance of teaching about testing from alumni survey data," Norsk informatikkonferanse (NIK), 2013.

[P5] C. Watson, K. Blincoe, "Attitudes towards software engineering education in the New Zealand industry," in 28th Annual Conference of the Australasian Association for Engineering Education (AAEE 2017), 2017, pp. 785-792.
[P6] R. Colomo-Palacios, C. Casado-Lumbreras, P. Soto-Acosta, F. J. García-Peñalvo, E. Tovar-Caro, "Competence gaps in software personnel: A multi-organizational study," Computers in Human Behavior, vol. 29, no. 2, pp. 456-461, 2013.

[P7] M. E. McMurtrey, J. P. Downey, S. M. Zeltmann, W. H. Friedman, "Critical skill sets of entry-level IT professionals: An empirical examination of perceptions from field personnel," Journal of Information Technology Education: Research, vol. 7, pp. 101-120, 2008.

[P8] D. M. Lee, E. M. Trauth, D. Farwell, "Critical skills and knowledge requirements of IS professionals: a joint academic/industry investigation," MIS quarterly, pp. 313-340, 1995.

[P9] K. Jones, L. N. Leonard, G. Lang, "Desired Skills for Entry Level IS Positions: Identification and Assessment," Journal of Computer Information Systems, vol. 58, no. 3, pp. 214-220, 2018.

[P10] R. D. Howard, "Does the information systems curriculum meet business needs: Case study of a southeastern college," PhD thesis, Capella University, 2017.

[P11] C. Scaffidi, "Employers' need for computer science, information technology and software engineering skills among new graduates," International Journal of Computer Science, Engineering and Information Technology (IJCSEIT), vol. 8, no. 1, pp. 1-12, 2018.

[P12] F. Patacsil, C. L. S. Tablatin, "Exploring the importance of soft and hard skills as perceived by IT internship students and industry: A gap analysis," JOTSE, vol. 7, no. 3, pp. 347-368, 2017.

[P13] A. Radermacher, "Evaluating the gap between the skills and abilities of senior undergraduate computer science students and the expectations of industry," PhD thesis, North Dakota State University, 2012.

[P14] R. Colomo-Palacios, E. Tovar-Caro, Á. García-Crespo, J. M. Gómez-Berbís, "Identifying technical competences of IT Professionals: the case of software engineers," International Journal of Human Capital and Information Technology Professionals (IJHCITP), vol. 1, no. 1, pp. 31-43, 2010.

[P15] G. Lang, K. Jones, L. N. Leonard, "In the know: Desired skills for entry-level systems analyst positions," Issues in Information Systems, vol. 16, no. 1, pp. 142-148, 2015.

[P16] M. Stevens, R. Norman, "Industry expectations of soft skills in IT graduates: a regional survey," in Proceedings of the Australasian Computer Science Week Multiconference, ACM, 2016, pp.13-21.

[P17] J. Liebenberg, M. Huisman, E. Mentz, "Industry's perception of the relevance of software development education," TD: The Journal for Transdisciplinary Research in Southern Africa, vol. 11, no. 3, pp. 260-284, 2015.

[P18] A. Radermacher, G. Walia, D. Knudson, "Investigating the skill gap between graduating students and industry expectations," in Companion Proceedings of the 36th International Conference on Software Engineering, ACM, 2014, pp. 291-300.

[P19] C. L.Aasheim, L. Li, J. D. Shropshire, C. A. Kadlec, "IT program curriculum recommendations based on a survey of knowledge and skill requirements for entry-level IT workers," Information Technology Faculty Publications, Paper 11, 2011.

[P20] C. V. Bullen, T. Abraham, K. Gallagher, J. C. Simon, P. Zwieg, "IT workforce trends: Implications for curriculum and hiring," Communications of the association for information systems, vol. 20, pp. 545-554, 2007.

[P21] C. L. Aasheim, S. R. Williams, "Knowledge and skill requirements for entry-level information technology workers: do employers in the IT industry view these differently than employers in other industries?," Journal of Information Systems Education, vol. 20, no. 3, pp. 349-356, 2009.

[P22] C. L. Aasheim, S. Williams, E. S. Butler, "Knowledge and skill requirements for IT graduates," Journal of Computer Information Systems, vol. 49, no. 3, pp. 48-53, 2009.

[P23] J. Liebenberg, M. Huisman, E. Mentz, "Knowledge and Skills Requirements for Software Developer Students," International 
Journal of Social, Behavioral, Educational, Economic, Business and Industrial Engineering, vol. 8, no. 8, pp. 2604-2609, 2014.

[P24] A. Radermacher, G. Walia, D. Knudson, "Missed expectations: where CS students fall short in the software industry," CrossTalk: The Journal of Defense Software Engineering, vol. 28, no. 1, pp. 4-8, 2015.

[P25] T. C. Lethbridge, "Priorities for the education and training of software engineers," Journal of Systems and Software, vol. 53, no. 1 , pp. 53-71, 2000.

[P26] S. Hanna, H. Jaber, A. Almasalmeh, F. A. Jaber, "Reducing the gap between software engineering curricula and software industry in Jordan," Journal of Software Engineering and Applications, vol. 7, pp. 602-616, 2014.

[P27] O. Minor, J. Armarego, "Requirements Engineering: a close look at industry needs and a model curricula," Australasian Journal of Information Systems, vol. 13, no. 1, pp. 192-208, 2005.

[P28] J. Liebenberg, M. Huisman, E. Mentz, "Software: university courses versus workplace practice," Industry and Higher Education, vol. 29, no. 3, pp. 221-235, 2015.

[P29] A. Begel, B. Simon, "Struggles of new college graduates in their first software development job," In ACM SIGCSE Bulletin, vol. 40, no. 1, pp. 226-230, 2008.

[P30] J. Liebenberg, M. Huisman, E. Mentz, "The relevance of software development education for students," IEEE Transactions on Education, vol. 58, no. 4, pp. 242-248, 2015.

[P31] T. C. Lethbridge, "The relevance of software education: A survey and some recommendations," Annals of Software Engineering, vol. 6, no. 1-4, pp. 91-110, 1998.

[P32] A. Seffah, "Training developers in critical skills," IEEE software, vol. 16, no. 3, pp. 66-70, 1999.

[P33] T. C. Lethbridge, "What knowledge is important to a software professional?," Computer, vol. 33, no. 5, pp. 44-50, 2000.

[P34] S. Surakka, "What subjects and skills are important for software developers?," Communications of the ACM, vol. 50, no. 1, pp. 73-78, 2007.

[P35] M. Daneva, C. Wang, P. Hoener, "What the job market wants from requirements engineers?: an empirical analysis of online job ads from the netherlands," in Proceedings of the 11th ACM/IEEE International Symposium on Empirical Software Engineering and Measurement, 2017, pp. 448-453.

\section{Bibliography}

Accreditation Board for Engineering and Technology (ABET), "ABET," in http://www. abet.org/accreditation/, Last accessed: Feb. 2019.

Adams, J., et al., 2016. Searching and synthesising 'grey literature' and 'grey information' in public health: critical reflections on three case studies. Syst. Rev. 5 (1), 164 Journal article.

A. f. C. M. Joint Task Force on Computing Curricula and I. C. Society, Computer Science Curricula 2013: Curriculum Guidelines for Undergraduate Degree Programs in Computer Science. ACM, 2013, p. 518.

Alain, A., Pierre, B., Robert, D., James, W.M., 2001. Guide to the Software Engineering Body of Knowledge (SWEBOK), Version 1. IEEE Press.

Alain, A., Pierre, B., Robert, D., James, W.M., 2004. Guide to the Software Engineering Body of Knowledge (SWEBOK), Version 2. IEEE Press.

American Society for Training Development, "Bridging the skills gap: help wanted, skills lacking: why the mismatch in today's economy?," Technical report, https://www.nist.gov/sites/default/files/documents/mep/Bridging-theSkills-Gap_2012.pdf, 2012.

Aničić, K.P., Divjak, B., Arbanas, K., 2017. Preparing ICT graduates for real-world challenges: results of a meta-analysis. IEEE Trans. Educ. 60 (3), 191-197.

Ardis, M., Budgen, D., Hislop, G.W., Offutt, J., Sebern, M., Visser, W., 2015. SE 2014: curriculum guidelines for undergraduate degree programs in software engineering. IEEE Comp. 48 (11), 106-109.

Association for Computing Machinery (ACM), Computer engineering curricula 2004, in https://www.acm.org/binaries/content/assets/education/curricularecommendations/ce-final-report.pdf, 2004.

Association for Computing Machinery (ACM), Computer engineering curricula 2016, in https://www.acm.org/binaries/content/assets/education/ce2016-finalreport.pdf, 2016.

Baker, J., 2018's software engineering talent shortage- it's quality, not just quantity," https://hackernoon.com/2018s-software-engineering-talent-shortage-itsquality-not-just-quantity-6bdfa366b899, Last accessed: Feb. 2019.
Beckman, K., Coulter, N., Khajenoori, S., Mead, N.R., 1997. Collaborations: closing the industry-academia gap. IEEE Softw. 14 (6), 49-57.

Benamati, J.H., Ozdemir, Z.D., Smith, H.J., 2010. Aligning undergraduate IS curricula with industry needs. Commun. ACM 53 (3), 152-156.

Bereiter, C., Scardamalia, M., 2006. Education for the knowledge age: design-centered models of teaching and instruction. In: Handbook of educational psychology, Mahwah, NJ, US. Lawrence Erlbaum Associates Publishers, pp. 695713.

Boehm, B., 2006. A view of 20th and 21st century software engineering. In: Proceedings of the international conference on Software engineering, pp. 1229.

Bourque, P., Fairley, R.E., 2014. Guide to the Software Engineering Body of Knowledge (SWEBOK), Version 3.0. IEEE Computer Society Press.

Briand, L., 2012. Embracing the engineering side of software engineering. IEEE Softw. 29 (4), $96-96$.

Cruzes, D.S., Dyba, T., 2010. Synthesizing evidence in software engineering research. In: Proceedings of International Symposium on Empirical Software Engineering and Measurement, pp. 1-10.

Cruzes, D.S., Felderer, M., Oyetoyan, T.D., Gander, M., Pekaric, I., 2017. How is security testing done in agile teams? A cross-case analysis of four software teams. In: Agile Processes in Software Engineering and Extreme Programming, pp. 201-216.

Doğan, S., Betin-Can, A., Garousi, V., 2014. Web application testing: a systematic literature review. J. Syst. Softw. 91, 174-201.

Easterbrook, S., Singer, J., Storey, M.-A., Damian, D., 2008. Selecting empirical methods for software engineering research. In: Shull, F., Singer, J., Sjøberg, D.I.K. (Eds.), Guide to Advanced Empirical Software Engineering. Springer London, London, pp. 285-311.

Faulk, S.R., 2000. Achieving industrial relevance with academic excellence: lessons from the Oregon master of software engineering. In: Proceedings of International Conference on Software Engineering, pp. 293-302.

Felderer, M., Fourneret, E., 2015. A systematic classification of security regression testing approaches. Int. J. Softw. Tools Tech. Transf. 17 (3), 305-319.

Felderer, M., Zech, P., Breu, R., Büchler, M., Pretschner, A., 2015. Model-based security testing: a taxonomy and systematic classification. Softw. Test. Verificat Reliab..

Ford, G., Gibbs, N.E., 1989. A master of software engineering curriculum. IEEE Comp 22 (9), 59-71.

Garg, A.X., Hackam, D., Tonelli, M., 2008. Systematic review and meta-analysis: when one study is just not enough. Clinic. J . Am. Soc. Nephrol. 3 (1), 253260.

Garousi, V., Mäntylä, M.V. , 2016a. Citations, research topics and active countries in software engineering: a bibliometrics study. Elsev. Comp. Sci. Rev. 19, 5677.

Garousi, V., Mäntylä, M.V. , 2016b. When and what to automate in software testing? A multivocal literature review. Inf. Softw. Technol. 76, 92-117.

Garousi, V., Mathur, A., 2010. Current state of the software testing education in north American academia and some recommendations for the new educators. In: Proceedings of IEEE Conference on Software Engineering Education and Training, pp. 89-96.

Garousi, V., Amannejad, Y., Betin-Can, A., 2015. Software test-code engineering: a systematic mapping. J. Inform. Softw. Technol. 58, 123-147.

Garousi, V., Petersen, K., Özkan, B., 2016. Challenges and best practices in industry-academia collaborations in software engineering: a systematic literature review. Inf. Softw. Technol. 79, 106-127.

Garousi, V., Eskandar, M.M., Herkiloğlu, K. , 2017a. Industry-academia collaborations in software testing: experience and success stories from Canada and Turkey. Softw. Qual. J. 25 (4), 1091-1143.

Garousi, V., Felderer, M., Hacaloğlu, T. , 2017b. Software test maturity assessment and test process improvement: a multivocal literature review. Inf. Softw. Technol. 85, 16-42.

Garousi, V., Felderer, M., Karapıçak, Ç.M., Yılmaz, U., 2018. Testing embedded software: a survey of the literature. Inf. Softw. Technol. In Press

Garousi, V., Giray, G., Tüzün, E., Catal, C., Felderer, M. Closing the gap between software engineering education and industrial needs, IEEE Software, In press, Preprint: https://arxiv.org/abs/1812.01954, 2019.

Garousi, V. , 2010a. An open modern software testing laboratory courseware: an experience report. In: Proceedings of the IEEE Conference on Software Engineering Education and Training, pp. 177-184.

Garousi, V. , 2010b. Applying peer reviews in software engineering education: an experiment and lessons learned. IEEE Trans. Educ. 53 (2), 182-193.

Garousi, V., 2011. Incorporating real-world industrial testing projects in software testing courses: opportunities, challenges, and lessons learned. In: Proceedings of the IEEE Conference on Software Engineering Education and Training (CSEE\&T), pp. 396-400.

Garousi, V., 2015. A bibliometric analysis of the Turkish software engineering research community. Spring. J. Scientomet. 105 (1), 23-49.

Giray, G., Tüzün, E., Garousi, V., 2016. Assessment of the Turkish software engineering university programs using the SWEBOK guide. In: Proceedings of the Turkish National Software Engineering Symposium (in Turkish), pp. 574-585.

Glass, G.V., 1976. Primary, secondary, and meta-analysis of research. Educ. Res. 5 (10), 3-8.

Godin, K., Stapleton, J., Kirkpatrick, S.I., Hanning, R.M., Leatherdale, S.T., 2015. Applying systematic review search methods to the grey literature: a case study examining guidelines for school-based breakfast programs in canada. Syst. Rev. 4, 138-148. 
Greenhalgh, T., Peacock, R., 2005. Effectiveness and efficiency of search methods in systematic reviews of complex evidence: audit of primary sources. BMJ 331 (7524), 1064-1065.

Groves, R.M., 2004. Survey Errors and Survey Costs. John Wiley \& Sons.

Häser, F., Felderer, M., Breu, R., 2014. Software paradigms, assessment types and non-functional requirements in model-based integration testing: a systematic literature review. In: presented at the Proceedings of the International Conference on Evaluation and Assessment in Software Engineering.

Haddaway, N.R., Collins, A.M., Coughlin, D., Kirk, S., 2015. The role of Google scholar in evidence reviews and its applicability to grey literature searching. PLoS ONE 10 (9).

Heredia, A., Palacios, R.C., de Amescua Seco, A., 2015. A systematic mapping study on software process education. In: Proceedings of the International Workshop on Software Process Education, Training and Professionalism, pp. 7-17.

Hire, I., Mind the gap: aA report on the UK's technology skills landscape, www. hired.com/skills-gap, Last accessed: Feb. 2019.

Institute for Electrical and Electronic Engineers (IEEE-CS) and Association for Computing Machinery (ACM), 2004. Curriculum guidelines for undergraduate degree programs in software Engineering: software engineering (SE) 2004. Computing Curricula Series http://sites.computer.org/ccse/.

Jacsó, P., 2005. Google scholar: the pros and the cons. Online Inform. Rev. 29 (2), 208-214.

Katz, R.L., 2009. Skills of an Effective Administrator. Harvard Business Review Press.

Kim, Y., Hsu, J., Stern, M., 2006. An update on the IS/IT skills gap. J. Inform. Syst. Educ. 17 (4), 395.

Kitchenham, B., Charters, S., Guidelines for performing systematic literature reviews in software engineering, in EBSE Technical Report, 2007, vol. EBSE-2007-01.

Li, P.L., Ko, A.J., Zhu, J., 2015. What makes a great software engineer? In: Proceedings of International Conference on Software Engineering, pp. 700-710.

Mahood, Q., Van Eerd, D., Irvin, E., 2014. Searching for grey literature for systematic reviews: challenges and benefits. Res. Synth. Methods 5 (3), 221-234.

Malik, B., Zafar, S., 2012. A systematic mapping study on software engineering education. In: Proceedings of World Academy of Science, Engineering and Technology, 6, pp. 3343-3353.

Marques, M.R., Quispe, A., Ochoa, S.F., 2014. A systematic mapping study on practical approaches to teaching software engineering. In: IEEE Frontiers in Education Conference, pp. 1-8.

Miles, M.B., Huberman, A.M., Saldana, J., 2014. Qualitative Data Analysis: A Methods Sourcebook, 3rd ed. SAGE Publications Inc.

Miller, J., 2000. Applying meta-analytical procedures to software engineering experiments. J. Syst. Softw. 54 (1), 29-39.

Ouhbi, S., Idri, A., Fernández-Alemán, J.L., Toval, A., 2015. Requirements engineering education: a systematic mapping study. Req. Eng. 20 (2), 119-138.

Parnas, D.L., 1999. Software engineering programs are not computer science programs. IEEE Softw. 16 (6), 19-30.

Petersen, K., Feldt, R., Mujtaba, S., Mattsson, M., 2008. Systematic mapping studies in software engineering. presented at the 12th International Conference on Evaluation and Assessment in Software Engineering (EASE).
Petersen, K., Vakkalanka, S., Kuzniarz, L., 2015. Guidelines for conducting systematic mapping studies in software engineering: an update. Inf. Softw. Technol. 64 (0), $1-18$.

Radermacher, A., Walia, G., 2013. Gaps between industry expectations and the abilities of graduates. In: Proceeding of ACM technical symposium on Computer science education, pp. 525-530.

Radermacher, A.D., 2012. Evaluating the gap between the skills and abilities of senior undergraduate computer science students and the expectations of industry MSc thesis. North Dakota State University.

Sabin, M., Alrumaih, H., Impagliazzo, J., Lunt, B.M., Tang, C., Zhang, M., 2015. ACM/IEEE-CS information technology curriculum 2017: a status update. In: presented at the Proceedings of the 16th Annual Conference on Information Technology Education. Chicago, Illinois, USA.

Seiler, R., 2005. Getting results with 360 assessments. Law Enforce. Tech. 32 (9), 148 $150,152-156$.

Sobel, A.E.K., "Software engineering education knowledge (SEEK)," http://sites computer.org/ccse/know/FinalDraft.pdf, 2003, Last accessed: Feb. 2019.

Topi, H., et al., 2010. Curriculum Guidelines for Undergraduate Degree Programs in Information Systems. ACM.

Tuzun, E., Erdogmus, H., Ozbilgin, I.G., 2018. Are computer science and engineering graduates ready for the software industry?: experiences from an industrial student training program. In: Proceedings of the International Conference on Software Engineering: Software Engineering Education and Training, pp. 68-77.

Wohlin, C., Regnell, B., 1999. Achieving industrial relevance in software engineering education. In: Proceedings of Conference on IEEE Software Engineering Education and Training, pp. 16-25.

Wohlin, C., 2014. Guidelines for snowballing in systematic literature studies and a replication in software engineering. In: presented at the Proceedings of the 18th International Conference on Evaluation and Assessment in Software Engineering. London, England, United Kingdom.

Zhi, J., Garousi, V., Sun, B., Garousi, G., Shahnewaz, S., Ruhe, G., 2015. Cost, benefits and quality of software development documentation: a systematic mapping. $J$. Syst. Softw. 99, 175-198.

Vahid Garousi is Associate Professor in Wageningen University, the Netherlands.

Görkem Giray is an Independent Researcher in Turkey,

Eray Tüzün is Associate Professor in Department of Computer Engineering, Bilkent University, Turkey.

Cagatay Catal is Associate Professor in Wageningen University, the Netherlands.

Michael Felderer is Professor in University of Innsbruck, Austria \& Blekinge Institute of Technology, Sweden. 